\title{
INVESTIGATING THE ROLE OF BIOFEEDBACK AND HAPTIC STIMULATION IN MOBILE PACED BREATHING TOOLS
}

\author{
A Thesis \\ by \\ ANTOINETTE LEANNA BUMATAY
Submitted to the Office of Graduate and Professional Studies of Texas A\&M University in partial fulfillment of the requirements for the degree of
MASTER OF SCIENCE

$\begin{array}{ll}\text { Chair of Committee: } & \text { Jinsil Hwaryoung Seo } \\ \text { Committee Members: } & \text { Philip Galanter } \\ & \text { Thomas Ferris } \\ \text { Head of Department: } & \text { Tim McLaughlin }\end{array}$

August 2015

Major Subject: Visualization

Copyright 2015 Antoinette Leanna Bumatay 


\begin{abstract}
Previous studies have shown that mindfulness meditation and paced breathing are effective tools for stress management. There are a number of mobile applications currently available that are designed to guide the breath to support these relaxation practices. However, these focus mainly on audio/visual cues and are mostly noninteractive. Our goal is to develop a mobile paced breathing tool focusing on the exploration of haptic cues and biofeedback. We conducted user studies to investigate the effectiveness of the system. This study explores the following questions: Do users prefer control of the breathing rate interval through an on-screen slider (manual mode) or through a physiological sensor (biofeedback mode)? How effective is haptic guidance on its own? And how may the addition of haptic feedback enhance audio-based guidance? Our analysis suggests that while both manual and biofeedback modes are desirable, manual control leads to a greater overall increase in relaxation. Additionally, the findings of this study support the value of haptic guidance in mobile paced breathing tools.
\end{abstract}




\section{DEDICATION}

I dedicate this thesis to my parents, Antonio and Connie Bumatay, for their infinite love and support. I would also like to extend this dedication to Angelica Bato for her humor and aide in centering my mind. Lastly, I would like to dedicate this thesis to Remy Chan for his incredible patience and love. Without his encouragement, I would have never applied to graduate school in the first place. 


\section{ACKNOWLEDGEMENTS}

I would like to thank my committee chair, Dr. Seo, and my committee members, Professor Galanter, and Dr. Ferris for additional support throughout the course of this research. I would also like to thank Dr. Quek and Dr. Chu for lending their wisdom in aide of my user study design, Shiyan Yang and Rhushabh Bhandari for their sensor recommendation, and Tracey Hodges for her writing advice and critiques. I also want to extend my gratitude to all the university students who were interested and willing to participate in the study. Thanks also go to my friends, colleagues, and the Visualization department faculty and staff for making my time at Texas A\&M University a memorable experience. 


\section{NOMENCLATURE}

$\begin{array}{ll}\text { BR } & \text { Breathing Rate } \\ \text { BPM } & \text { Breaths Per Minute } \\ \text { HRV } & \text { Heart Rate Variance } \\ \text { SDK } & \text { Software Developer Kit }\end{array}$




\section{TABLE OF CONTENTS}

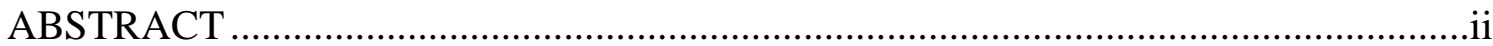

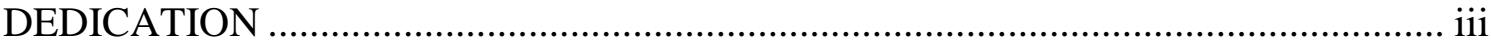

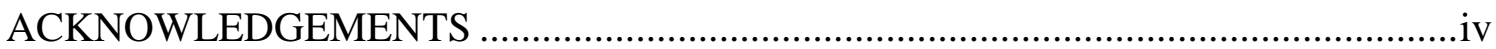

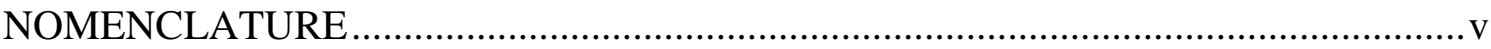

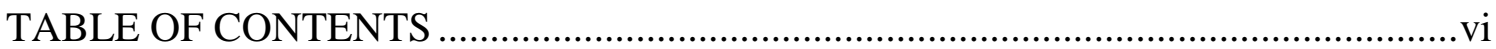

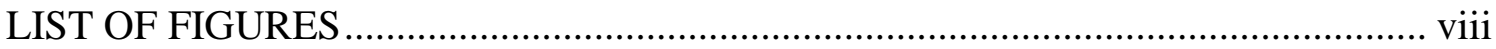

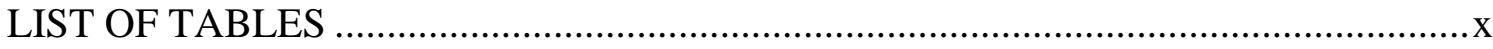

INTRODUCTION

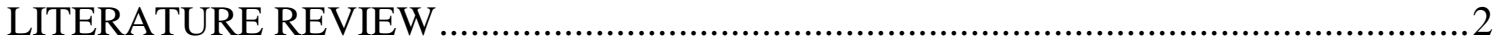

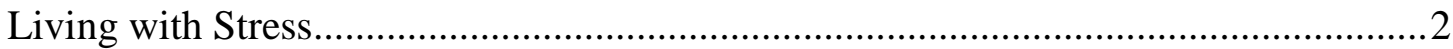

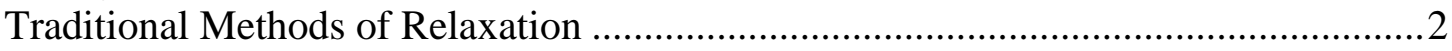

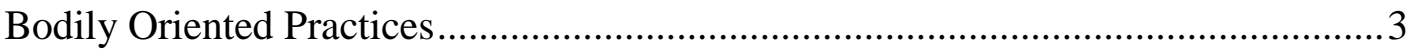

Paced Breathing ...........................................................................................

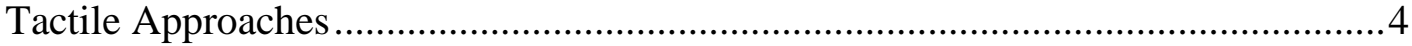

Technology Driven Methods of Relaxation ..............................................................

Interactive Methods through Biofeedback ………….............................................

Innovative Methods of Mobile Tools for Paced Breathing .......................................

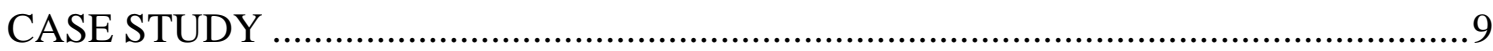

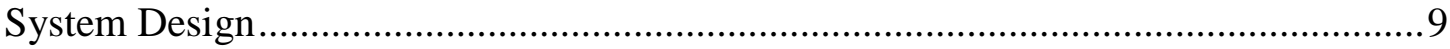

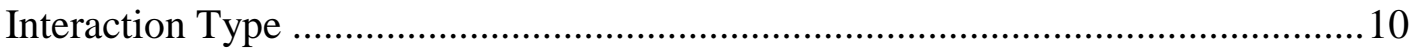

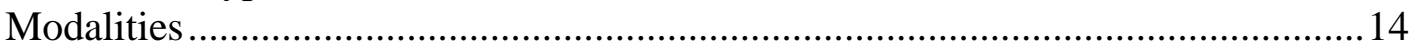

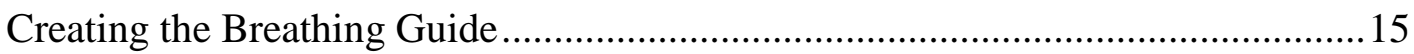

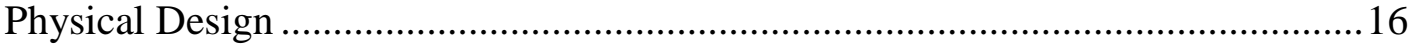

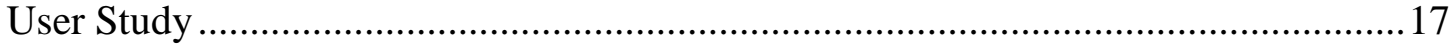

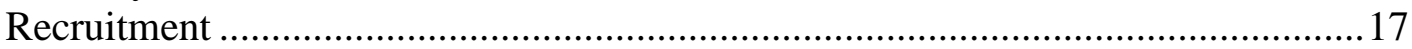

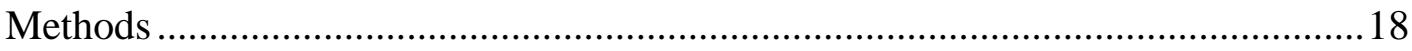

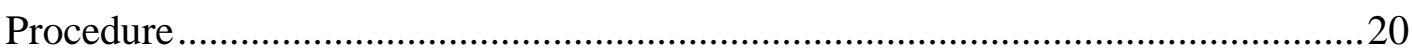




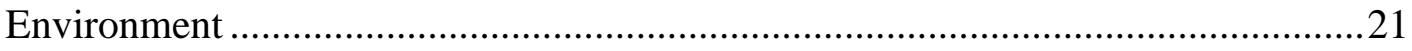

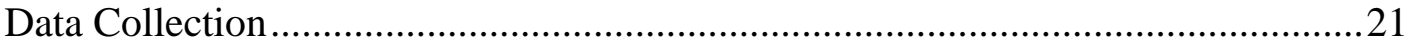

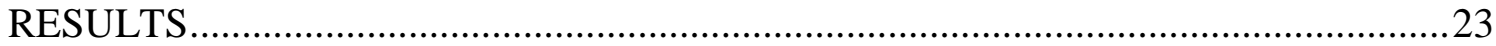

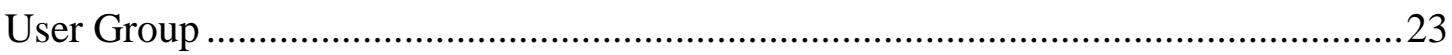

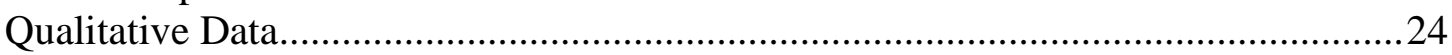

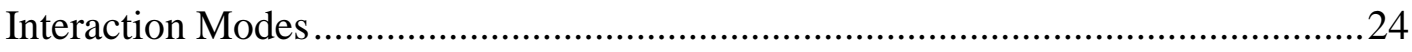

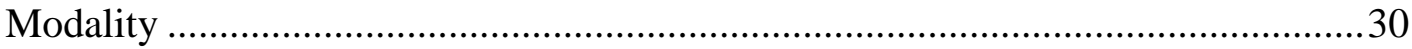

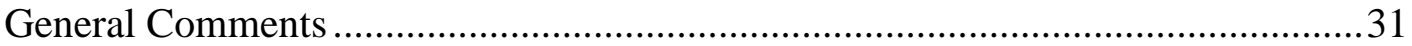

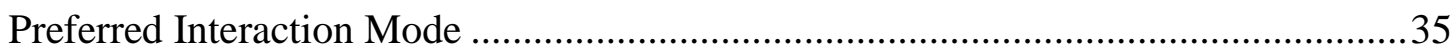

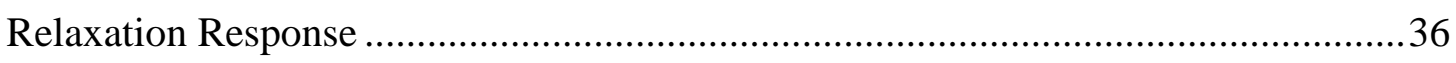

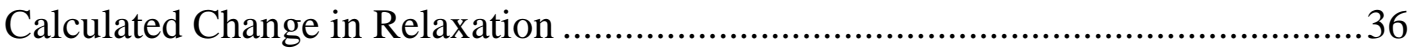

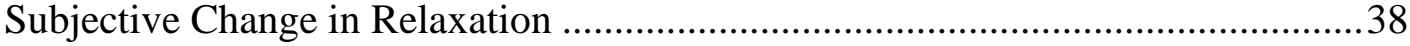

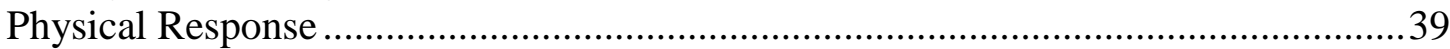

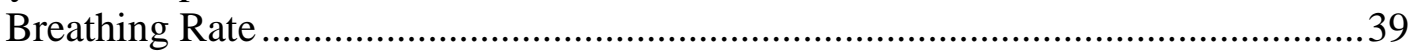

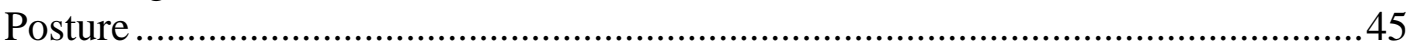

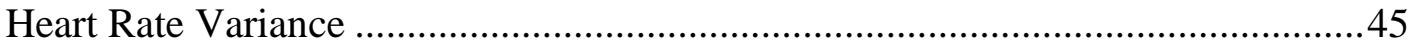

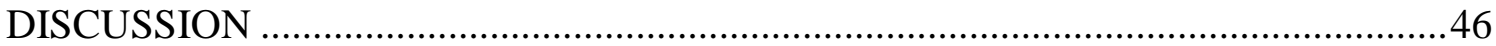

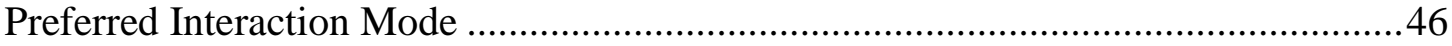

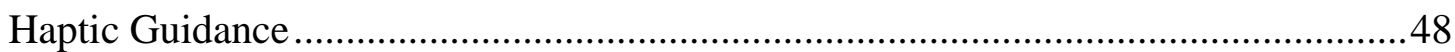

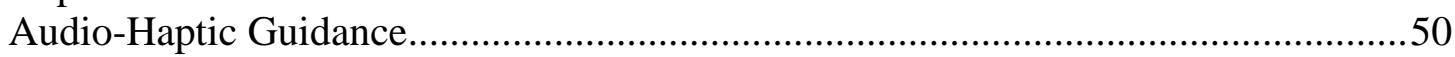

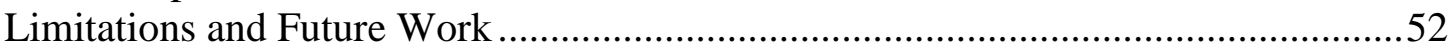

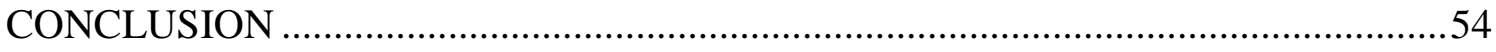

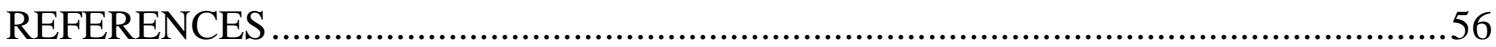

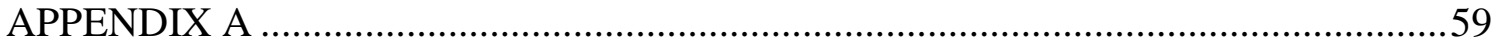

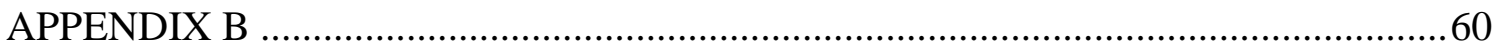

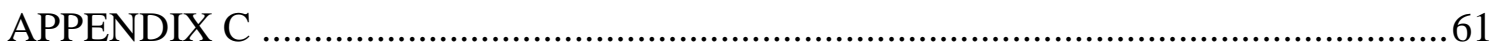




\section{LIST OF FIGURES}

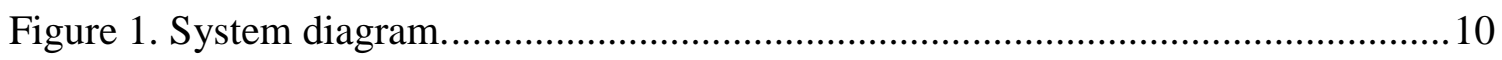

Figure 2. Screenshot of slider used to adjust breathing rate in manual interaction mode.

Figure 3. Application user flow for manual interaction. ...............................................11

Figure 4. Application user flow for biofeedback interaction. ...........................................13

Figure 5. Audio and haptic patterns for each group .....................................................15

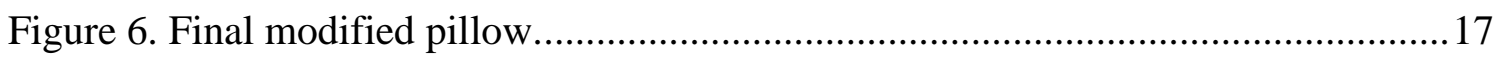

Figure 7. Participant comments about what they liked about the manual interaction mode.

Figure 8. Participant comments about what they disliked about the manual interaction mode.

Figure 9. Participant comments about what they liked about the biofeedback interaction mode. DB: Deep Breathing.

Figure 10. Participant comments about what they disliked about the biofeedback interaction mode.

Figure 11. Participant comments about what they generally liked about the application.

Figure 12. Participant responses to using this application daily.

Figure 13. Participant responses on recommending the application to family or friends.

Figure 14. Reasons why participants would use the application daily.............................35

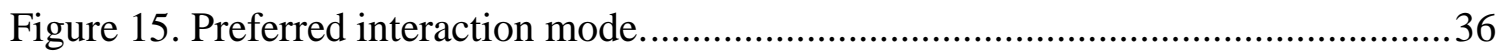

Figure 16. Average mean increase in calculated relaxation..............................................37

Figure 17. Average increase in subjective relaxation. ....................................................39 
Figure 18. Graph descriptions of breathing rate (BR) over the session duration: (a) flat, (b) gradual, and (c) bumpy............................................................... 40

Figure 19. Breakdown of sessions for each breath pattern description.........................43

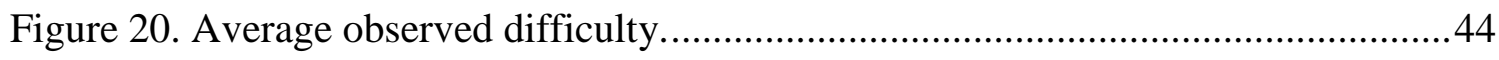




\section{LIST OF TABLES}

Page

Table 1. Division of participants based on general level of stress and deep breathing

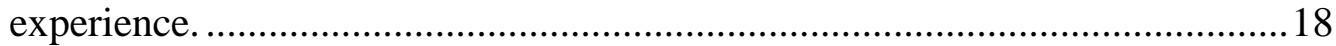

Table 2. Descriptions of user study cases......................................................... 19

Table 3. Group timeline and division of user study cases....................................... 19

Table 4. Gender division among modality groups. ................................................23

Table 5. Average emotional and physical results between genders ..............................24

Table 6. Average highest, lowest, and change in breathing rate (BR) values by group and interaction mode.

Table 7. Examples of graph descriptions for manual and biofeedback interaction sessions. 


\section{INTRODUCTION}

Stress is physical response that affects us all in varying degrees throughout our lifetime. Throughout history, people have developed various practices to cope with stress. Many of these focus on bringing awareness to the body and breath. Studies have shown that mindfulness meditation and paced breathing are effective tools for stress management (Grossman, 2004; Brown, 2005; Goldin, 2010).

Within the past year there have been huge strides in development and commercial interest regarding health and fitness portable tools (Pitstick, 2015). There are a number of commercial mobile apps currently available designed to guide the breath to support mindfulness meditation and paced breathing practices; however, these focus mainly on audio and visual cues and are non-interactive. And those that are interactive are functional in the sense that they read and display biometric data, but do not use this data to further tailor the experience to the user.

Overall, there has been limited research done towards integrating paced breathing with technology, especially in the realm of haptic use and interactivity in portable paced breathing tools. This study will focus on exploring this area by investigating the following questions: What is the role of biofeedback and haptic stimulation in mobile paced breathing tools? Do users prefer controlling the breathing rate interval of the guide through an on-screen slider (manual mode) or through a physiological sensor (biofeedback mode)? How effective is haptic rhythm guidance on its own? How may the addition of haptic feedback enhance audio-based guidance? 


\section{LITERATURE REVIEW}

The purpose of this section is to review the literature regarding innovative methods of relaxation. First, we will address the need of relaxation tools due to the universal experience of stress. We will then provide a brief overview of traditional methods used for relaxation. This is contrasted with the discussion of current technology driven methods for relaxation.

\section{Living with Stress}

Chronic exposure to stress during any stage of life has a negative impact on cognitive and mental health (Lupien, 2009). According to the American Psychology Association, from 2007 to 2012, adults consistently reported their own stress level to be higher than what they believed to be healthy. In 2012, adults rated their own stress level to be 4.9 and a healthy stress level to be 3.6 on a 10-point scale (where 1 is "little to no stress" and 10 is "a great deal of stress"). Approximately 72 percent of adults surveyed report that their stress level has increased or remained constant in the past five years, and 80 percent in the past year. 20 percent report extreme levels of stress. And only 37 percent feel they are doing an excellent or very good job of stress management (The Impact of Stress, 2015). The data reported here support the need for available tools to help control stress.

\section{Traditional Methods of Relaxation}

As stress is undeniably universal, there have been many techniques and practices previously developed to assist in stress management and promotion of relaxation. This 
section focuses on traditional relaxation methods involving the body, the breath, and the sense of touch.

\section{Bodily Oriented Practices}

The use of manipulating and/or bringing awareness to the body to help calm the mind is a common theme in traditional relaxation methods. Through the centuries, physical practices have persevered as a common release of stress. The most well-known of these practices is likely yoga. Yoga consists of mental, physical, and spiritual elements. Although there are many variations, ultimately yoga is considered a moving meditation, focusing on the body and the breath. According to many in the field, yoga is an effective tool in improving stress, anxiety, and mental health, and comparable to other relaxation therapies such as cognitive behavioral therapy. (Granath, 2006; Smith, 2007). Similarly, the Chinese martial art tai chi is another type of moving meditation, bringing awareness to the breath and movements. Studies have also indicated that tai chi exercise may lead to improvements in stress and overall wellbeing (Jin, 1992; Sandlund, 2000). Progressive muscle relaxation training is another technique that involves slowly tensing and releasing different muscle groups throughout the body. This has also been shown to improve psychological health and quality of life (Cheung, 2003). Through the tenacity of these traditional practices, there is evidence to suggest that the relationship of the mind to the body is important for engaging a relaxation state.

\section{Paced Breathing}

A common point between the previously mentioned practices is the breath. It appears that this is one of our primary contacts with our parasympathetic nervous 
system. Often during bouts of stress or panic attacks, our sympathetic nervous system activates "fight or flight" mode. Breathing is the only component of the autonomic nervous system that can be controlled consciously. Practicing yogic paced breathing or mindfulness daily can help form a habit that will be useful during a panic attack, as control of the breath stimulates the vagus nerve which interfaces with the parasympathetic nervous system that is in control of "rest and digest" mode. In other words, this helps trigger a relaxation response (Seaward, 2008). Paced breathing has been shown to be a valid tool in managing stress and anxiety (Grossman, 2004; Brown, 2005; Goldin, 2010).

\section{Tactile Approaches}

The relationship of the body to its environment can be obtained through bringing awareness to the senses. Aural and visual stimulation for relaxation have been deeply investigated in research. Although, tactile exploration is underexplored in this particular area, there is some evidence of touch being incorporated in traditional relaxation practices. Touch is an extremely personal and intimate sense. It is used to create a personal space, only experienced to those directly exposed to the action. The use of therapeutic touch is often used to help people relax (Gagne, 1994; Meek, 1993). Similarly, the tactile sense has also been incorporated in meditation through the physical manipulation of objects with the hands, such as the creation of a zen garden or the handling of Baoding/meditation balls and prayer beads (Wernik, 2009). 


\section{Technology Driven Methods of Relaxation}

Recently, there has been a rise in interest in self-monitoring and selfmanagement, as well as non-illness focused methodologies to mental health. In this age of technology and innovation, there exists a lot of opportunity to supplement existing practices. In this section we will discuss the importance of biofeedback by reviewing previous studies and commercial products. We then review current innovative methods for paced breathing applications for mobile devices, and identify holes in the literature that need investigation.

\section{Interactive Methods through Biofeedback}

Before delving into the various interactive installations and portable devices, an important distinction must be clarified between adaptive and functional interactivity. This distinction is adapted from Tim Guay's Web Publishing Paradigm. In the case of a functional system, "the user interacts with the system to accomplish a goal or set of goals." The user is provided feedback on their progress towards the goal. In the case of meditation and paced breathing systems, the user is provided a guide, and is made aware of their performance through some form. Although Guay recognizes that "the boundary between functional and adaptive interactivity is blurred," the primary difference between the two is that the adaptive system will modify its own behavior based on some input from the user (Romberger, n.d.).

\section{Functional Interactivity}

A few applications are available commercially that offer functional interactivity. The company HeartMath has developed an iPhone application called Inner Balance that 
uses an ear sensor to capture Heart Rate Variability. The application offers visual guidance for the breath of an expanding and contracting colorful wheel. It also shows real time feedback of the user's heart rate (Inner Balance, 2013). HeartMath also offers a standalone device line entitled emWave. This device also uses heart rate data and provides feedback through graphs and light. It also has an additional software component that allows access to coherence games (emWave Technology, 2015). RESPeRATE is another commercial paced breathing application. It has a breath sensor and features a simple display with breathe in/out graphics and audio tones to aide in pacing the breath (What is RESPeRATE, 2014).

\section{Adaptive Interactivity}

In a study entitled Breathe with the Ocean, three different systems were investigated: a fixed-rate breathing guidance system, an adaptive breathing following system, and an adaptive-rate breathing guidance system. The system featured an environment with audio (ocean wave sounds), haptic (touch blanket), and visual (light) stimuli. It was found that a lack of personalization in a breathing guidance system appeared to be a significant drawback since different users have quite different inhale/exhale patterns and optimal respiration rates. A user can easily become dizzy and uncomfortable if they force their breath to follow a rate or pattern that they cannot adapt to.

Aside from breathing guidance systems, there have been other attempts to help the user bring awareness to their breath through an adaptive system. Sonic Cradle is a large installation designed to cultivate a meditative experience. The user was instructed 
to wear a breath sensor and was invited to lie in a hammock in a chamber of complete darkness. Users were able to shape peaceful soundscapes using their own respiration (Vidyarthi et al., 2012). Although there has been limited exploration in the area of adaptive interactivity in portable meditation tools, there is a work-in-progress paper featuring the Heartbeat Sphere (Thieme et al., 2012). It was catered toward women with a diagnosed learning disability and borderline personality disorder. Mindfulness skills are a vital component of their therapy. The Heartbeat Sphere is spherical object designed to assess and reflect a person's heart rate through soft pulsing vibrations and colorful lights. This is intended to invite the user to be mindful of her heartbeat. This paper only presented the concept design. An evaluation study is currently not available.

\section{Innovative Methods of Mobile Tools for Paced Breathing}

There has been some effort in consumer companies as well as the academic community to incorporate technology in non-interactive and interactive systems specifically for paced breathing. The primary systems covered in this section focuses on various portable handheld devices that are designed to bring awareness to the user of their own breath.

There are numerous commercial mobile phone applications available in the Google Play Store and the Apple App Store that offer paced breathing guidance (Appendix A). All the mobile phone applications investigated incorporate an option for audio guidance. Audio utilized ranges from guided meditation voice narrative to natural sounds (e.g. water, birds) to percussive sounds (e.g. bell chimes, gongs, meditation bowls). Visual guidance often appears in the form of meters filling and emptying, 
objects expanding and contracting, or animated graphs. Few offer haptic components, and those that do have abrupt pulses that feel jarring.

You Can't Force Calm (Wongsuphasawat et al., 2012) was an exploratory study that designed and evaluated techniques to support respiratory regulation to reduce stress and increase parasympathetic tone. It incorporated breath sensor input and visual and audio feedback. Evidence from this study supported that auditory guidance was more effective than visual at creating self-reported calm. This was attributed to the users' ability to effectively map sound to respiration, thereby reducing cognitive load and mental exertion. Although visual guidance led to more respiratory change, it resulted in less subjective calm. Thus, motivating users to exert physical or mental efforts may counter the calming effects of slow breathing. It would be interesting to further this exploration of mobile tools into the physical and subjective effects of haptic stimulation.

As mentioned previously, personalization of a breathing guidance system is important. Some commercial mobile phone applications (Appendix A) offer an option to manually adjust the breathing interval; however, there are currently no mobile phone applications available that is similar to the adaptive system investigated in the installation Breathe with the Ocean (Dijk et al., 2010). With the rise in emerging technologies in portable fitness and health, this realm is worth further exploration. 


\section{CASE STUDY}

After investigating the existing literature, there were two obvious holes regarding mobile paced breathing tools: biofeedback interaction and haptic stimulation. The first aspect of this study is the concept of biofeedback interaction. Do users prefer manual control over a breathing interval of a paced breathing guide? Or would biofeedback control be more effective? In particular yogic breathing practices, the objective is to bring awareness to the present by focusing on the body and breath. If the biofeedback interactive system is successful, it would allow the user to focus solely on their breath and not be concerned or preoccupied about manipulating the system itself. The second aspect of this study is the exploration of haptics. As stated previously, the concentration has been on visual and audio feedback for similar systems. How effective is haptic rhythm guidance on its own? How may the addition of haptic feedback enhance audio based guidance?

\section{System Design}

A simple paced breathing application was built in Android Studio to aide in the exploration of these questions. We developed two modes of interaction: manual and biofeedback. The application also has the ability to produce an audio, haptic, or audiohaptic breathing guide. Figure 1 is a diagram of the overall system. 


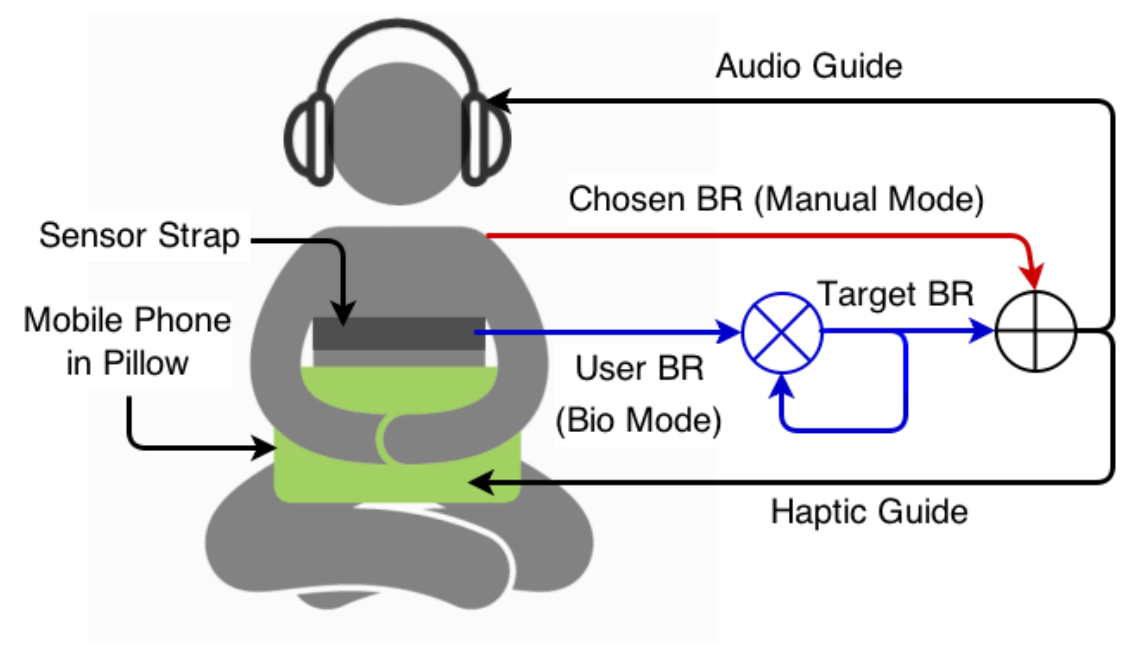

Figure 1. System diagram.

\section{Interaction Type}

\section{Manual Interaction}

In manual interaction mode the user is initially prompted to follow a standard breathing interval of 6 breaths per minute (BPM), an optimal breathing rate for higher HRV values. The user has the ability to manually lengthen or shorten the interval using an unmarked slider as shown in Figure 2. The user may adjust the interval at any time, and the breathing guide is immediately adjusted accordingly. Figure 3 illustrates the user flow planned for this interaction. 


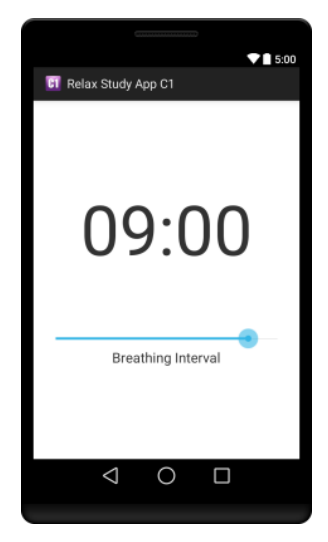

Figure 2. Screenshot of slider used to adjust breathing rate in manual interaction mode.

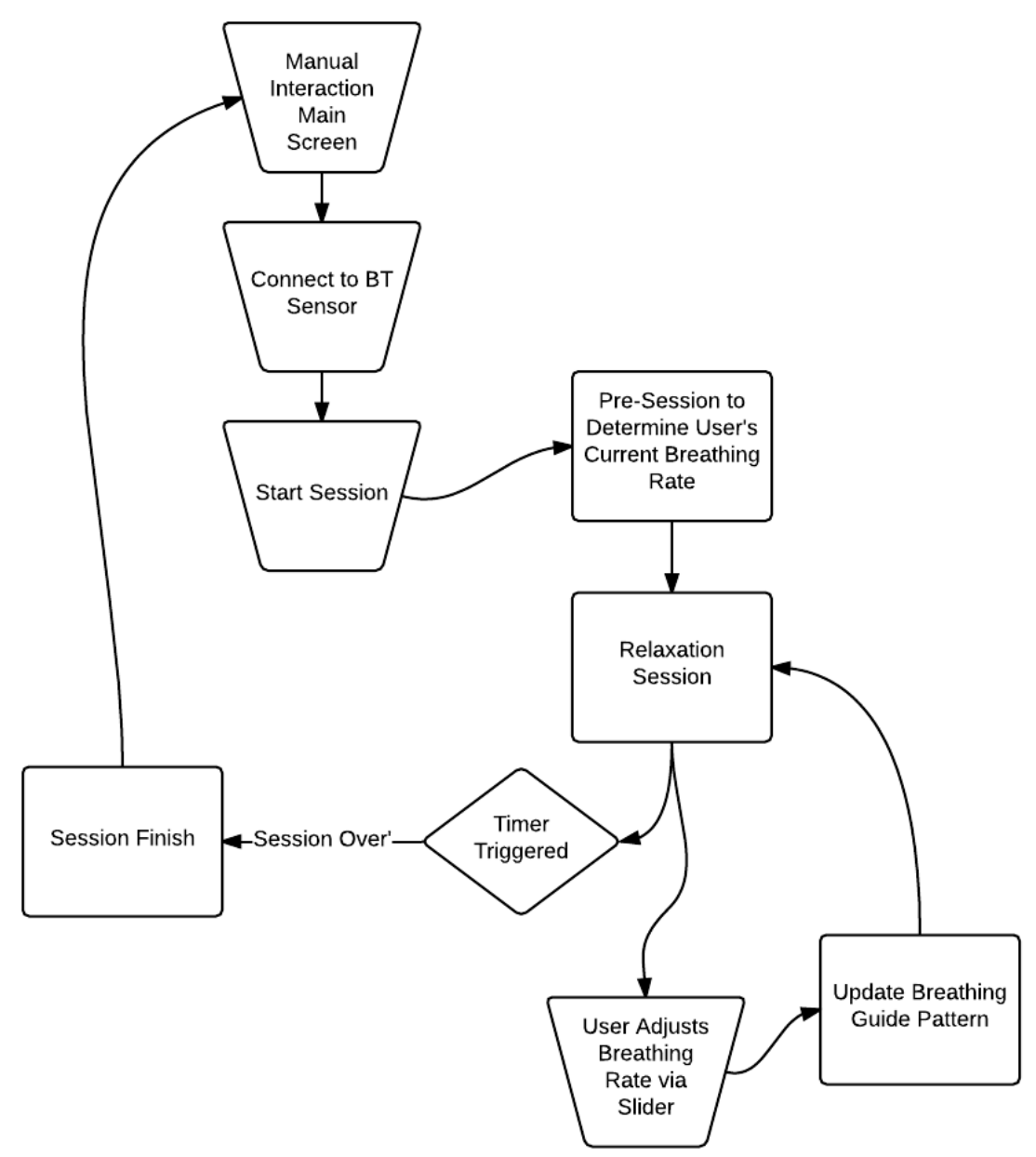

Figure 3. Application user flow for manual interaction. 


\section{Biofeedback Interaction}

Prior to the main session, the user is prompted to breathe regularly for one minute. During this time, the application determines the user's current breathing rate by communicating via Bluetooth with an external physiological sensor, the Zephyr

BioHarness 3. During the main session, the breathing guide is initially set to match the user's breathing rate, slowly increasing the interval to slow down the user's breath. In 30 second intervals throughout the duration of the session, the program monitors the user's ability to match the guide and adjusts the breathing interval accordingly. If the user is able to follow the guide, the breathing interval is increased, challenging the user to breathe even slower. If the user is close, but not quite matching the breathing interval, the breathing interval is unchanged. If the user is unable to breathe slow enough to match the breathing interval, the breathing interval is decreased. Figure 4 is a flowchart diagramming the behavior of the biofeedback system. 


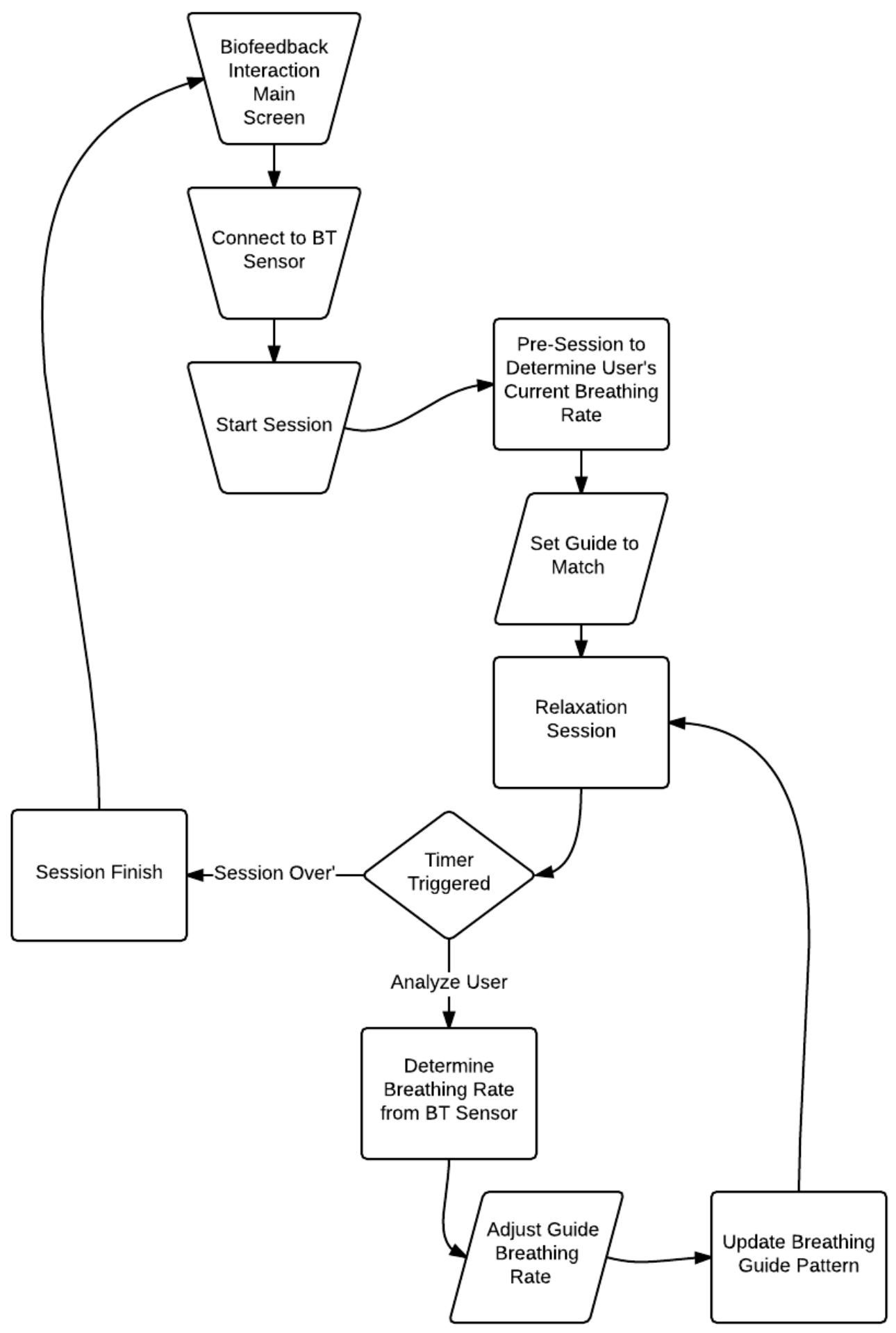

Figure 4. Application user flow for biofeedback interaction. 


\section{Modalities}

\section{Audio}

Sound is utilized in the majority of applications currently on the market.

Percussive sounds are a commonly associated with meditation and paced breathing. For this application, the gong chimes used were found on FreeSound.org by DJ Griffin. We decided on two similar gong sounds in different pitches to help distinguish the inhalation from the exhalation prompt. This choice was inspired from an Android application currently on the market called Paced Breathing.

\section{Haptics}

The Immersion Haptic Development Platform for Android was utilized in order to obtain control the vibration of the mobile phone's motor. After testing various haptic patterns, we decided to have the haptic sensations complement the audio. As it has been previously shown that vibration can enhance the experience of audio (Dijk et al. 2009; Dijk et al. 2010), we decided to have the vibrations mimic the gongs, ringing deeply then fading off. This was made possible by the MagSweepEffect function from the Immersion Haptic SDK. Figure 5 illustrates the audio and haptic patterns for each user group. 


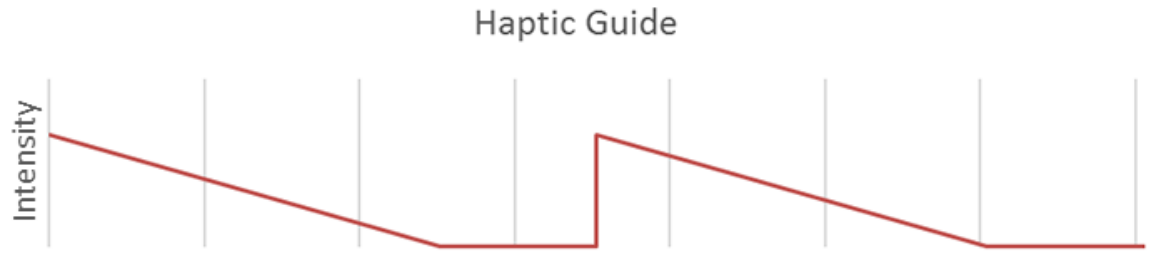

Audio Guide

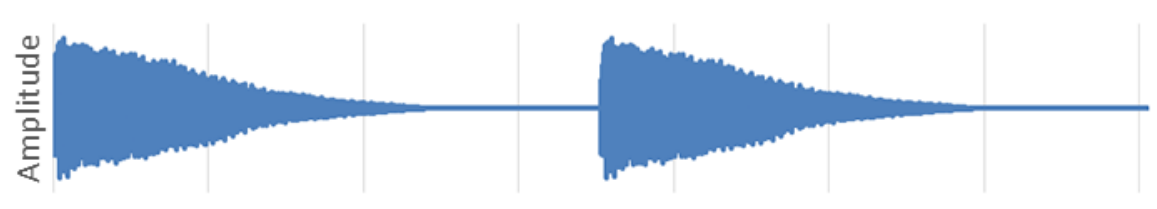

Breath

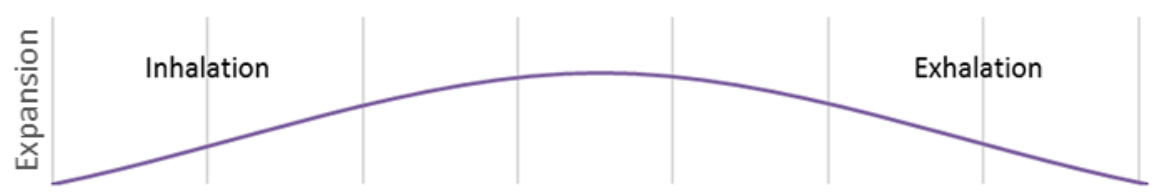

Figure 5. Audio and haptic patterns for each group.

\section{Creating the Breathing Guide}

In order to create the breathing guide, a timer was used in order to trigger the event. The produced event would include audio and/or haptics (Figure 5). The timer trigger interval was calculated based on the guide's breathing interval (Equation 1), where the breathing interval is milliseconds per breath and the breathing rate is in breaths per minute. The breathing interval was either chosen by the user via the onscreen slider (manual mode) or dependent on the user's breath via sensor (biofeedback mode) as explained in the biofeedback interaction section. 
Equation 1. Conversion of the breathing interval (milliseconds per breath) from the breathing rate (breaths per minute)

$$
\text { Breathing Interval }=\frac{60000}{\text { Breathing Rate }}
$$

\section{Physical Design}

After some preliminary user testing with the mobile phone application, we observed some awkwardness in holding a mobile phone for an extended period of time. We decided to create a pillow encasement for the phone in order to allow the user to fully relax with their hands comfortably wrapped around the pillow. This would also soften and amplify the phone's vibrations. A store-bought travel pillow was modified with a pocket along the seam to hold the mobile device in the center of the pillow. The pocket was created to be large enough to allow the user to slip the phone in and out of the pillow with ease. The small size of the pillow allows the user to rest their arms around the pillow against their abdomen. Depending on their grasp of the pillow, they can adjust the intensity of the haptic stimulation. A loose hold would create a low intensity, while a tighter hold would be higher in intensity. Figure 6 displays the final modified pillow in use by the participant. 

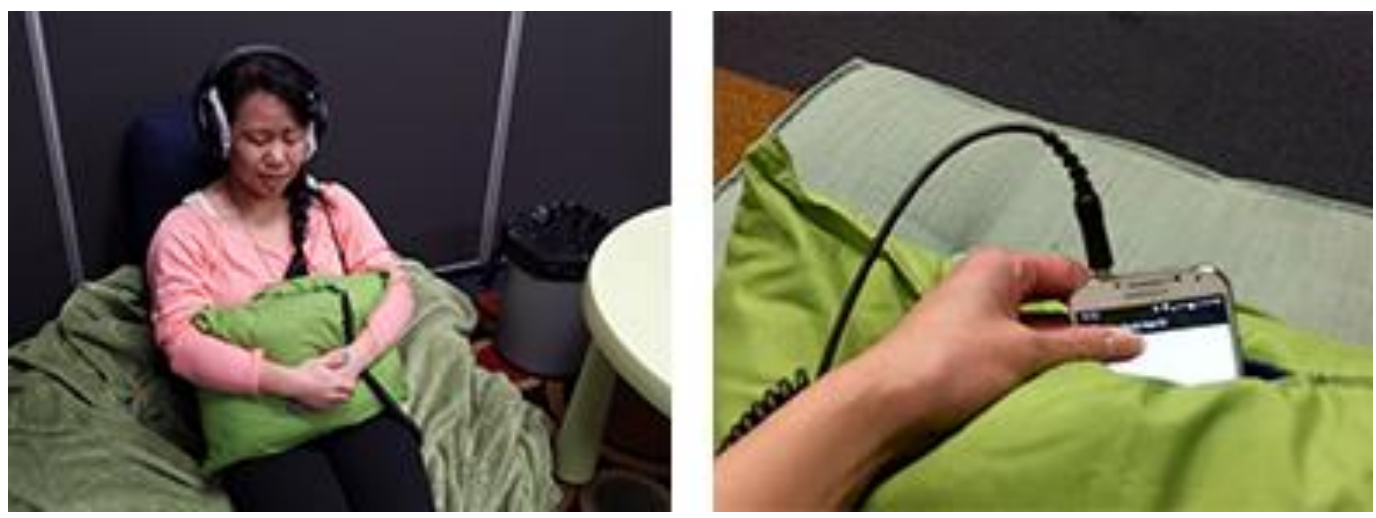

Figure 6. Final modified pillow.

\section{User Study}

\section{Recruitment}

We obtained 21 university students, 14 female and 7 male, for our user study. Users were recruited through the Texas A\&M University College of Architecture emailing list and word of mouth. Students voluntarily contacted the researcher. Users were separated into three different groups based on a short pre-filter questionnaire. The survey asked the user their self-identified general level of stress (low, medium, high). The participant also noted any previous experience in paced breathing techniques. Table 1 indicates the division of the participants. Each response was assigned a numerical value between 1 and 5. In the case of deep breathing experience, 1 indicated no experience and 5 indicated a lot of experience. In the case of general level of stress, 1 indicated very low stress level, while 5 indicated a very high stress level. Participants were divided in order to create balance between the three groups. The average deep 
breathing experience of Group 1,2, and 3 are all 2.4. The average general level of stress of Group 1, 2, and 3 are 3.3, 3.6, and 3.7 respectively.

Table 1. Division of participants based on general level of stress and deep breathing experience.

\begin{tabular}{|c|c|c|c|c|c|c|}
\hline & \multicolumn{2}{|c|}{ Group 1 } & \multicolumn{2}{c|}{ Group 2 } & \multicolumn{2}{c|}{ Group 3 } \\
\hline & $\begin{array}{c}\text { Deep } \\
\text { Breathing } \\
\text { Experience }\end{array}$ & $\begin{array}{c}\text { General } \\
\text { Stress Level }\end{array}$ & $\begin{array}{c}\text { Deep } \\
\text { Breathing } \\
\text { Experience }\end{array}$ & $\begin{array}{c}\text { General } \\
\text { Level of } \\
\text { Stress }\end{array}$ & $\begin{array}{c}\text { Deep } \\
\text { Breathing } \\
\text { Experience }\end{array}$ & $\begin{array}{c}\text { General } \\
\text { Level of } \\
\text { Stress }\end{array}$ \\
\hline $\mathbf{1}$ & Some & High & $\begin{array}{c}\text { Somewhat } \\
\text { often }\end{array}$ & $\begin{array}{c}\text { Above } \\
\text { average }\end{array}$ & None & High \\
\hline $\mathbf{2}$ & None & Average & Some & $\begin{array}{c}\text { Above } \\
\text { average }\end{array}$ & Some & $\begin{array}{c}\text { Above } \\
\text { average }\end{array}$ \\
\hline $\mathbf{3}$ & Some & Average & None & Low & Some & $\begin{array}{c}\text { Above } \\
\text { average }\end{array}$ \\
\hline $\mathbf{4}$ & None & High & $\begin{array}{c}\text { Somewhat } \\
\text { often }\end{array}$ & High & None & Low \\
\hline $\mathbf{5}$ & Some & Average & None & $\begin{array}{c}\text { Above } \\
\text { average }\end{array}$ & Some & High \\
\hline $\mathbf{6}$ & A lot & Low & Some & High & A lot & Average \\
\hline $\mathbf{7}$ & None & Average & None & $\begin{array}{c}\text { Below } \\
\text { Average }\end{array}$ & None & $\begin{array}{c}\text { Above } \\
\text { Average }\end{array}$ \\
\hline
\end{tabular}

\section{Methods}

The study concentrated on one dependent variable (stress) and two independent variables (device output and type of interaction). The possible device outputs included the following: haptic, audio, or audio-haptic. The interaction type included manual or biofeedback. Table 2 provides descriptions of each user study case. The study lasted 
three days for each participant. Table 3 illustrates the division of the cases among each group. Groups contained 3 to 4 participants each.

Table 2. Descriptions of user study cases.

Device Output

\begin{tabular}{|c|c|c|c|}
\cline { 2 - 4 } \multicolumn{1}{c|}{} & A Haptic & B Audio & C Both \\
\hline $\mathbf{1}$ Manual & $\begin{array}{c}\text { Device produces } \\
\text { vibration. } \\
\text { User can manually } \\
\text { adjust interval. }\end{array}$ & $\begin{array}{c}\text { Device produces } \\
\text { sound. } \\
\text { User can manually } \\
\text { adjust interval. }\end{array}$ & $\begin{array}{c}\text { Device produces } \\
\text { vibration and sound. } \\
\text { User can manually } \\
\text { adjust interval. }\end{array}$ \\
\hline $\begin{array}{c}\mathbf{2} \\
\text { Biofeedbac } \\
\mathbf{k}\end{array}$ & $\begin{array}{c}\text { Device produces } \\
\text { vibration } \\
\text { and changes interval } \\
\text { based on BR. }\end{array}$ & $\begin{array}{c}\text { Device produces } \\
\text { sound } \\
\text { and changes interval } \\
\text { based on BR. }\end{array}$ & $\begin{array}{c}\text { Devices produces } \\
\text { vibration and sound } \\
\text { and changes interval } \\
\text { based on BR. }\end{array}$ \\
\hline
\end{tabular}

Table 3. Group timeline and division of user study cases.

\begin{tabular}{|c|c|c|c|}
\hline Groups & Day 1 & Day 2 & Day 3 \\
\hline Group 1.1 & A1 & A2 & Choice of A1 or A2 \\
\hline Group 1.2 & A2 & A1 & Choice of A1 or A2 \\
\hline Group 2.1 & B1 & B2 & Choice of B1 or B2 \\
\hline Group 2.2 & B2 & B1 & Choice of B1 or B2 \\
\hline Group 3.1 & C1 & C2 & Choice of C1 or C2 \\
\hline Group 3.2 & C2 & C1 & Choice of C1 or C2 \\
\hline
\end{tabular}




\section{Procedure}

The user protocol of the overall study was as follows:

Day 1 ( 1 hour):

1. Short interview for user to expand on experience level in deep breathing and other stress management techniques.

2. Short introduction in proper breathing techniques for mindfulness meditation and paced breathing exercises for stress management.

3. Short survey.

4. User will put on sensor.

5. Short meditation sit (10 minutes).

6. User will take off sensor.

7. Short survey.

Day 2 ( 30 minutes):

1. Short survey.

2. User will put on sensor.

3. Short meditation sit (10 minutes).

4. User will take off sensor.

5. Short survey.

Day 3 ( 1 hour):

1. Short survey.

2. User will put on sensor.

3. Short meditation sit (10 minutes).

4. User will take off sensor.

5. Short survey.

6. Exit interview. 


\section{Environment}

Studies were conducting in the Emerging Technologies Building on the Texas A\&M University campus. Participants were invited to make themselves comfortable in the designated "relaxation station" filled with blankets and a variety of pillows (two floor, one bolster, one bed rest). In order to eliminate environmental noise from the hallways and rooms next door, the user was instructed to utilize noise isolating headphones (Shure SRH440 Professional Studio) and a small nearby speaker (Photive Hydra) played various brown and pink ambient noise tracks. The participant was left alone in the area to ensure additional privacy during use of the app.

\section{Data Collection}

Both quantitative and qualitative data were used for analysis. Quantitative data collected includes the following: user preference (choice on Day 3), sensor data (heart rate variance, breathing rate, posture), and a short survey (before and after each sit). The short survey (Appendix B) consisted of a 5-point Likert scale with a list of adjectives adapted from the Stress Arousal Checklist (King, 1983) and an analogue scale for the user to personally rate their relaxation level. Qualitative data was gathered through a series of on-site interviews (Appendix C). A preliminary interview was conducted during the first meeting in order for the user to expand on their experience level in deep breathing and other stress management techniques. Users also noted existing technologies they use to assist in relaxation and stress management. A general feedback interview was conducted at the end of each session to discuss the overall experience, what they enjoyed and what they disliked of that particular session. Only open-ended 
questions were asked. Users could opt to not make a comment. On Day 3 an exit interview was conducted to discuss the overall experience of participation throughout the study. The user elaborated on their last day interaction choice. They also noted what they specifically liked and disliked about both interaction versions of the application. The participant also indicated whether or not they would use this application in their daily lives, and if they would recommend it to their family or friends. They were also free to make any additional comments regarding their experience with the application and in the study. The recorded interview data was coded and analyzed focusing on key themes arising from the participants' experiences 


\section{RESULTS}

The results gathered from the conducted user study are divided into four main sections: user group, qualitative data, relaxation response, and physical response. To begin, we will discuss the user group gender distribution for each modality group. We will then review our qualitative data, addressing key themes that arose from participant responses in the exit interviews. Next, we will look into the relaxation responses from using the mobile phone application by examining both self-reported and calculated changes in relaxation from the pre and post session surveys. Lastly, we look at the physical responses gathered from the BioHarness sensor, focusing on the changes in breathing rate and emerging breathing patterns resulting from the application session.

\section{User Group}

Since the user groups were initially chosen to be purely divided based on the user's average stress level and previous experience with paced breathing practices, each group resulted in an unbalanced gender distribution (Table 4). However, the average emotional and physical results between each gender did not show a significant discrepancy (Table 5).

Table 4. Gender division among modality groups.

\begin{tabular}{|c|c|c|}
\hline Group & Male & Female \\
\hline Haptic & 4 & 3 \\
\hline Audio & 3 & 4 \\
\hline Audio-Haptic & 0 & 7 \\
\hline
\end{tabular}


Table 5. Average emotional and physical results between genders

\begin{tabular}{|c|c|c|}
\hline Average & Male & Female \\
\hline Increase in Self-Reported Relaxation & 3.5 & 3.6 \\
\hline Increase in Calculated Relaxation & 2.3 & 1.9 \\
\hline Decrease in BR & 10.4 & 10.7 \\
\hline
\end{tabular}

\section{Qualitative Data}

User interviews were transcribed and coded. Key phrases and themes were extracted from the answer for each open-ended question. All responses were divided into three main sections: interaction mode, breathing guide modality, and overall experience. Similar comments among participants were tabulated.

\section{Interaction Modes}

At the end of the first two sessions, the user was asked what they liked and disliked about the interaction mode they experienced for that day. On the last day, they were asked to again recall what they liked and disliked about each interaction mode, and expand on why they preferred one over the other.

\section{Manual}

Majority of participants had positive feedback about the manual interaction mode (Figure 7). Only five participants did not have any positive comments regarding the manual interaction. 


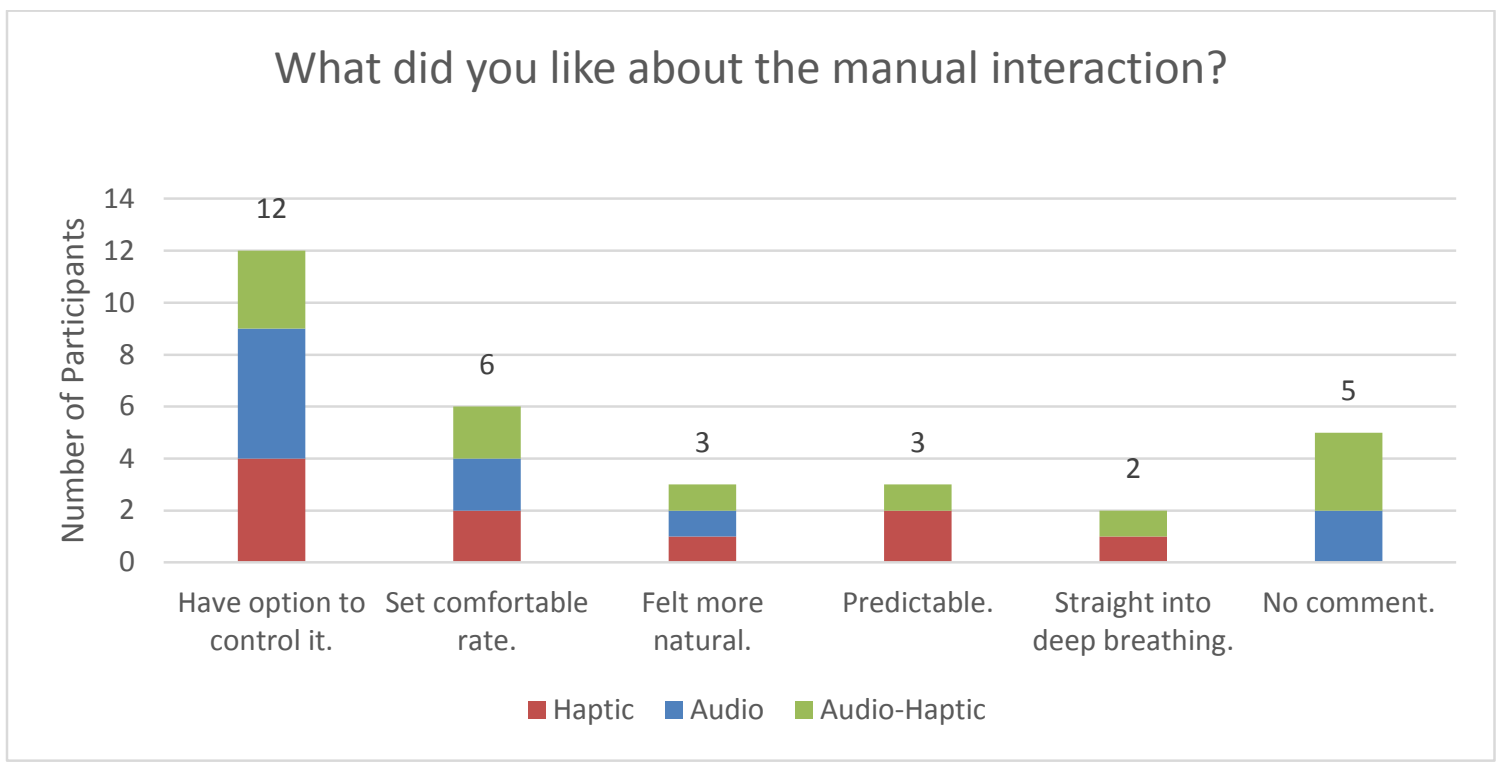

Figure 7. Participant comments about what they liked about the manual interaction mode.

Twelve users mentioned they liked having the ability to manually control the system, and six of them specifically added that they liked that they could set it at what they personally found comfortable. For instance, some revealed they did not feel comfortable taking long deep breaths at all, noting that they felt more relaxed when taking medium to shallow breaths. Participant R commented, "I liked how you could control the interval of the breathing, because some people just have massive lungs and other people just shallow breathe all the time... I am a shallow breather, so I just turned it down." Another three users noted that this mode was more natural for them to follow because the rhythm was steadier, as Participant $\mathrm{H}$ reflected, "The breathing became easier just because the gong noise kind of became 'Snap. Snap. Snap.' It became natural. I didn't have to think about it like I was last time. " Similarly, three users stated 
that they liked that the system was predictable. Two participants noted that they liked that they could go straight into the deep breathing, which Participant L noted allowed her to "... [become] relaxed faster during it. And so [she] was relaxed for longer."

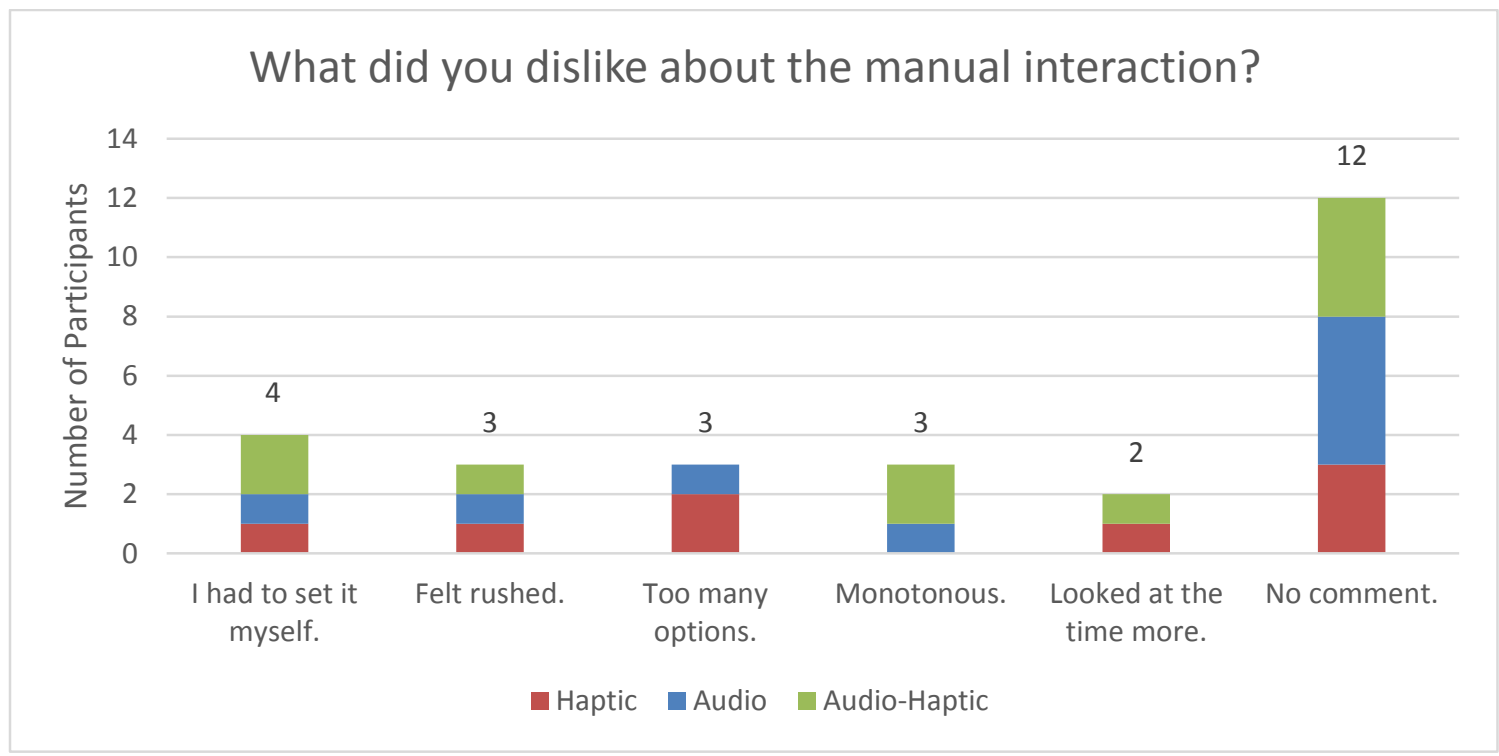

Figure 8. Participant comments about what they disliked about the manual interaction mode.

There were fewer negative comments regarding the manual interaction system (Figure 8). In fact twelve users had no negative comment to state at all. The remaining users had varying complaints about the manual interaction. Four participants did not like having to set it themselves at all. Participant S responded, "It wasn't great... I was very disappointed that it wouldn't like do it itself. I didn't like that. I didn't like doing it myself, because I'm more aware of the time. I'm more aware of looking. I'm looking at a device. And I want to get out of that." Additionally, three users felt rushed having to choose their 
own breathing rate due to the limited time in the session. Similarly, another three users felt like there were too many options, and were unsure of where to set it. Three users also mentioned that the system felt too monotonous and boring. Participant $\mathrm{R}$ commented, "[I disliked] that there was no sort of variable in it, so that your mind just got used to it and was able to like I don't know. Once it got used to it, it would start to wander because there was nothing to just keep you there." Two users stated they did not like that they ended up looking at the time more.

\section{Biofeedback Mode}

The majority of participants, fifteen users, had at least one positive comment to provide about the biofeedback interaction (Figure 9).

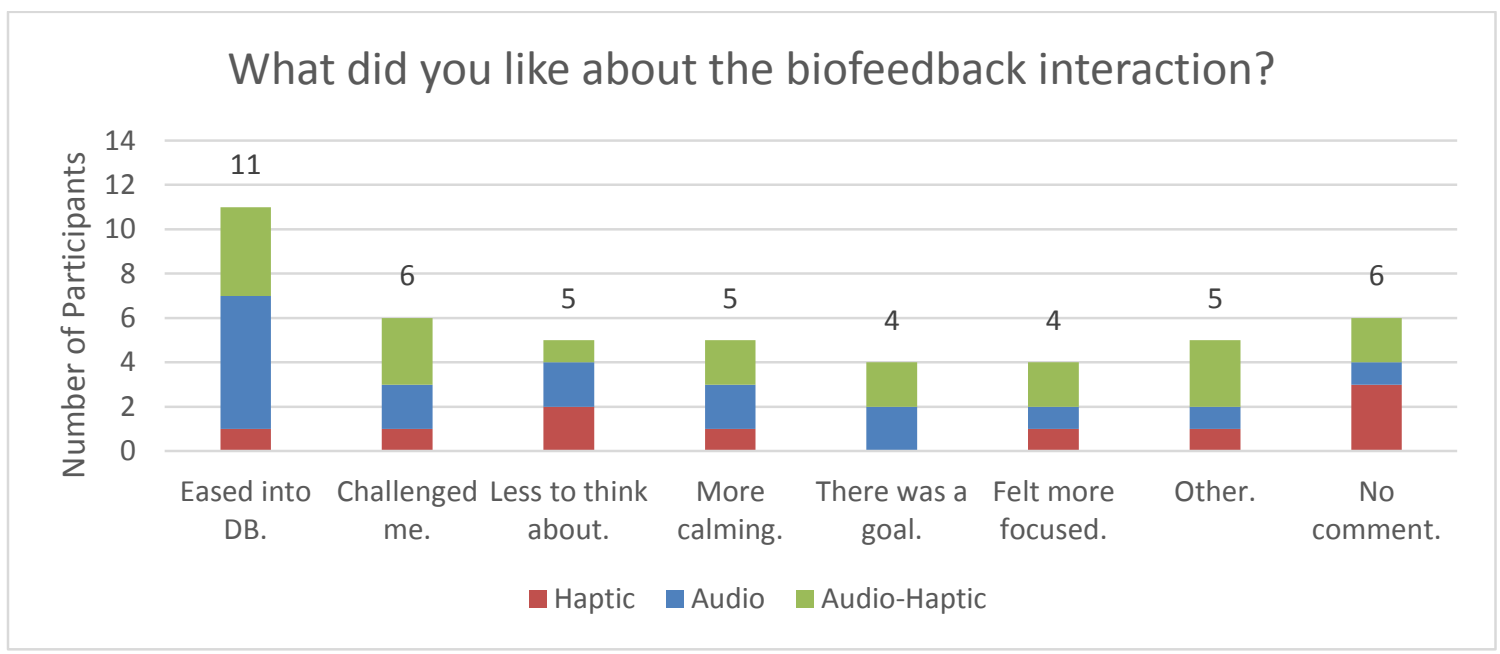

Figure 9. Participant comments about what they liked about the biofeedback interaction mode. DB: Deep Breathing. 
Eleven participants mentioned that they liked the idea of the application easing them into the deep breathing. Participant Q elaborated, "I felt that it calmed me down more. From going from a normal - what I would usually be breathing at - and then taking me down steadily. I liked that better than me having to think about it." Six participants reflected that they enjoyed how the system challenged them to help them breathe deeper. Another five users mentioned they liked that there was less to think about. Participant $\mathrm{O}$ explained, "It was better than [the manual interaction] ... it was automatic... so I don't have to deal with something. Or anything. How to set it or check the phone. I just have to follow the vibrations... So it was pretty good... you don't have to set anything again and again, so it's more peaceful." Five participants revealed they felt the biofeedback interaction was more calming. Participant Q recollected, "I felt like it was a lot more calming... It was just super soothing... I liked how it kind of changed it up so you weren't doing the same thing. " Four participants added that there was a goal or felt they were more focused. Participant M noted, "The changing of the breaths made me focus on the breathing a lot, which made me have to stop thinking about other things." A couple users noted that they liked the variation in the pattern, and another couple felt like the rhythm was more natural and less mechanic. Only six users made no comment regarding what they liked about the biofeedback interaction. 


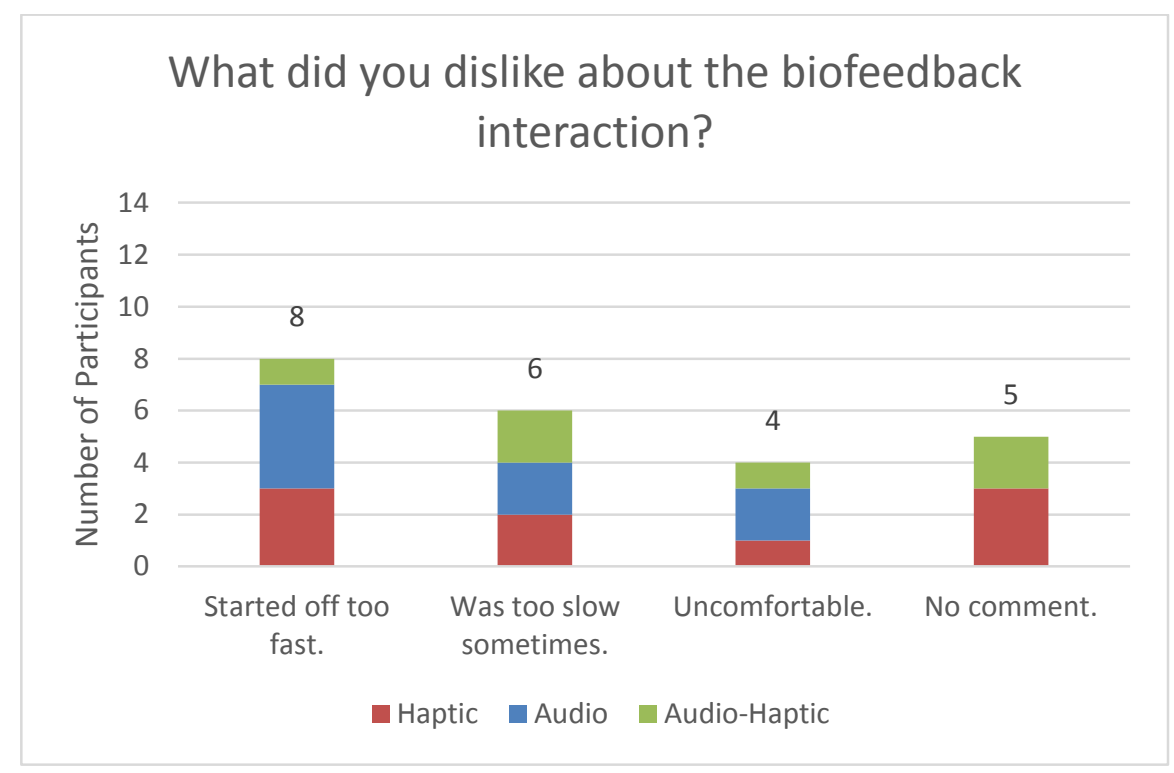

Figure 10. Participant comments about what they disliked about the biofeedback interaction mode.

The majority of participants also had some criticism regarding the biofeedback system (Figure 10). Eight participants commented that the pace of the breathing interval guide was too initially too quick. Participant B reflected, "It started off too fast for me... It felt like I had to hyperventilate at first, though this is an exaggeration obviously." Six participants felt that the system got too slow at points, leading four participants to feel uncomfortable. Participant R commented, "[The biofeedback mode] was a little more difficult. It would gong for you and you would breathe in and then you're waiting for the gong again and you're like getting uncomfortable holding your breath." Only five participants did not have a negative comment. 


\section{Modality}

To iterate, each user only experienced one type of modality for the duration of the study. However, a few users made comments directly addressing the type of feedback they experienced.

\section{Haptic}

Three users commented that the vibration pulses from the pillow reminded them of a heartbeat or a cat purring. Participant A commented that she liked how subtle the vibrations felt, reflecting "Normally when I try to meditate on my own I get severely distracted. And I try to set a timer. Do a similar thing... But I liked how the vibrations made you aware that you were doing something. But you weren't really aware of it." One user initially disliked the vibrations because it reminded him of a phone ringing. $\mathrm{He}$ explained, "The phone vibrating itself is stressful to me. Because when a phone is vibrating it needs immediate attention, so... I'm not very comfortable with removing my stress with that type of stimulus." However, the same user said by the end of the session, "Once I remove it from that association, I was able to relax my body a little more."

\section{Audio}

A few people noted specifically that they did like the gong chimes, describing them as "environmental," "smooth," "relaxing," or "pleasant." However, some users did not like it at all. They felt it was not very entertaining and a little robotic. Three people said it would be nice if there was more to listen to, like natural sounds or background music. Participant P noted, "I liked the tones. But I kind of wanted something a little 
more to listen to... I liked the tones helped me focus. And stay on track. But it wasn't very entertaining to listen to."

\section{Audio-Haptic}

A couple participants commented how they liked how the sounds and the vibrations worked together, helping them feel more immersed. Participant B reflected, "It was so relaxing. The sounds and the vibrations made it easy to focus on something besides your thoughts. Or anything else. And it was very calming." Two people specified that the vibrations were actually their favorite part out of the audio-haptic system. They liked that there was an extra something they could feel to complement the sound. Participant $\mathrm{H}$ commented, "I actually found the gong noise a lot more relaxing. I guess maybe that's why I was able to really not think about it. But for some reason I realized this is actually a good noise. I like this. And I felt that had the vibrations not been there I don't know if it would have the same effect."

\section{General Comments}

Participants gave a lot of positive feedback about the general use of the application and the study overall (Figure 11). 


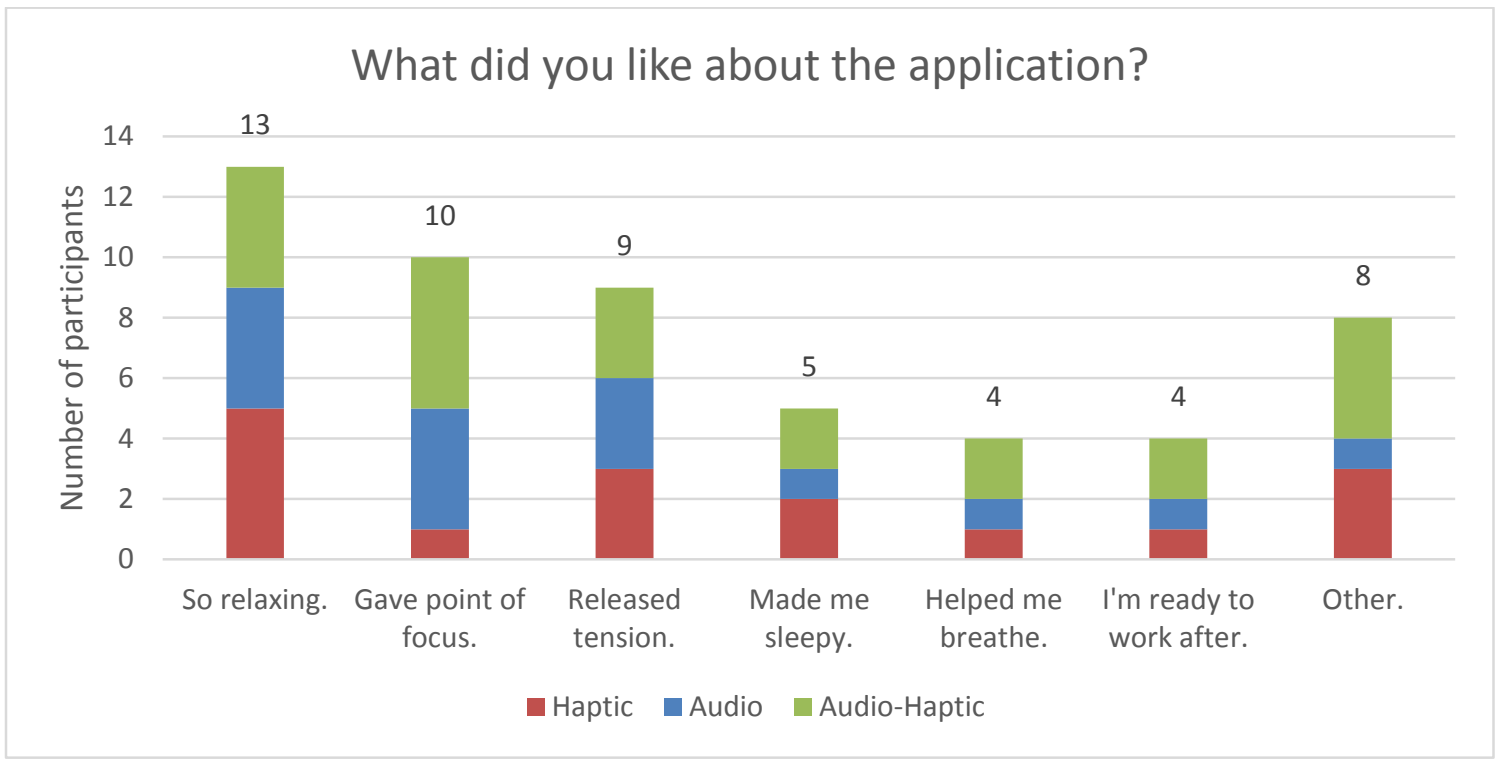

Figure 11. Participant comments about what they generally liked about the application.

Thirteen participants specifically mentioned they liked that it was so relaxing. Ten participants mentioned that they liked that it gave them a point of focus. Participant A said, "It was nice having something to follow instead of just doing the breathing by yourself. It was nice. It was something to keep you focused even though you were like so [relaxed]." Nine users stated that it helped them release tension. Participant T remarked, "My muscles started to relax. They were kind of tense at first and then I kind of just let go." Five participants said they felt sleepy afterwards and noted their relaxed state. Four users commented that it helped them breathe, and allowed them to be more aware of their breath outside of the study. Participant E stated, "[I liked] that it helps me breathe. Even when I was finish with the study. And I'd go outside... *takes deep breath* it's like... okay I can breathe. So that was nice." Another four participants felt refreshed and ready to work after using the app. There were a few miscellaneous comments. One 
participant remarked how she became so relaxed, she forgot where she was for a second. A couple users also mentioned they felt more energized, comfortable, or grounded.

Few of the general comments were negative. Two participants felt that the sensor was uncomfortable. Another stated the headphones were somewhat annoying. However, these participants additionally stated that the discomfort did not impede their ability to relax during the session.

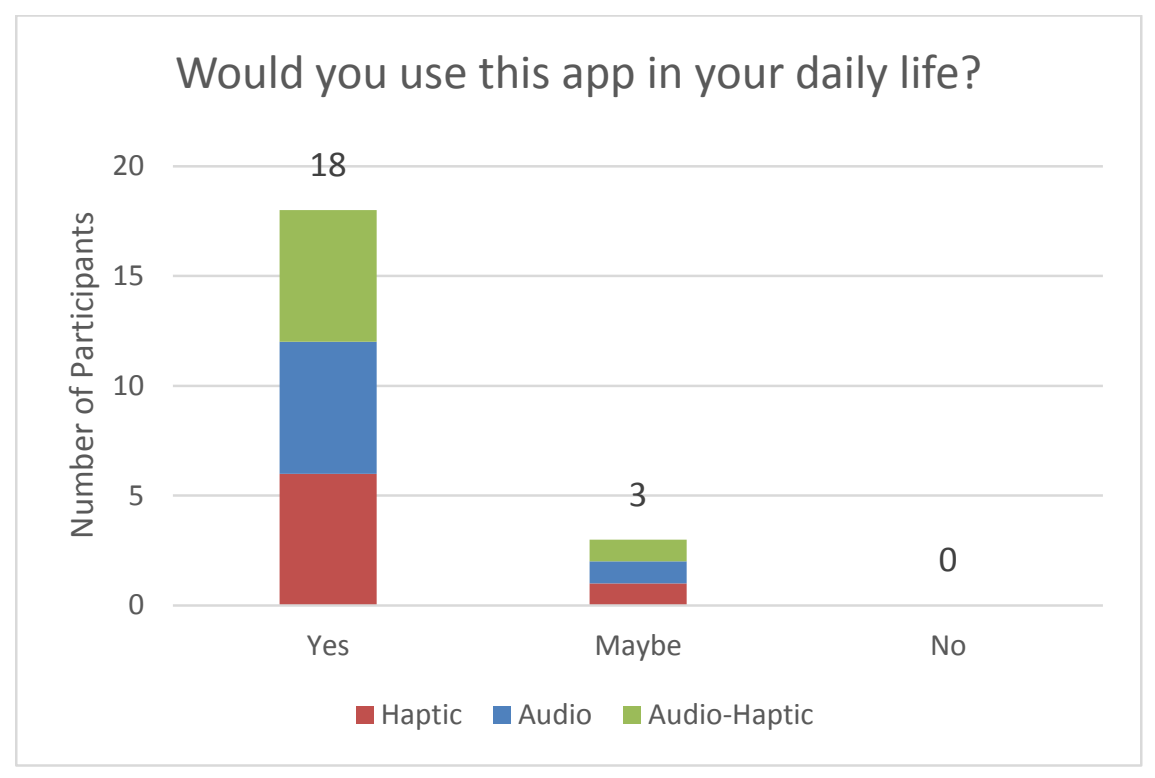

Figure 12. Participant responses to using this application daily.

All participants expressed desire for future use of the application in their personal life (Figure 12). Eighteen participants said that they would use this application in their daily life. The three participants replied they might use the application in their daily life. The maybe responses varied for each person. One person stated they do not use mobile phone applications. Another said that although they would not use it daily, they would 
use it only when they were stressed. The last participant stated they would use it only if they needed help going to sleep.

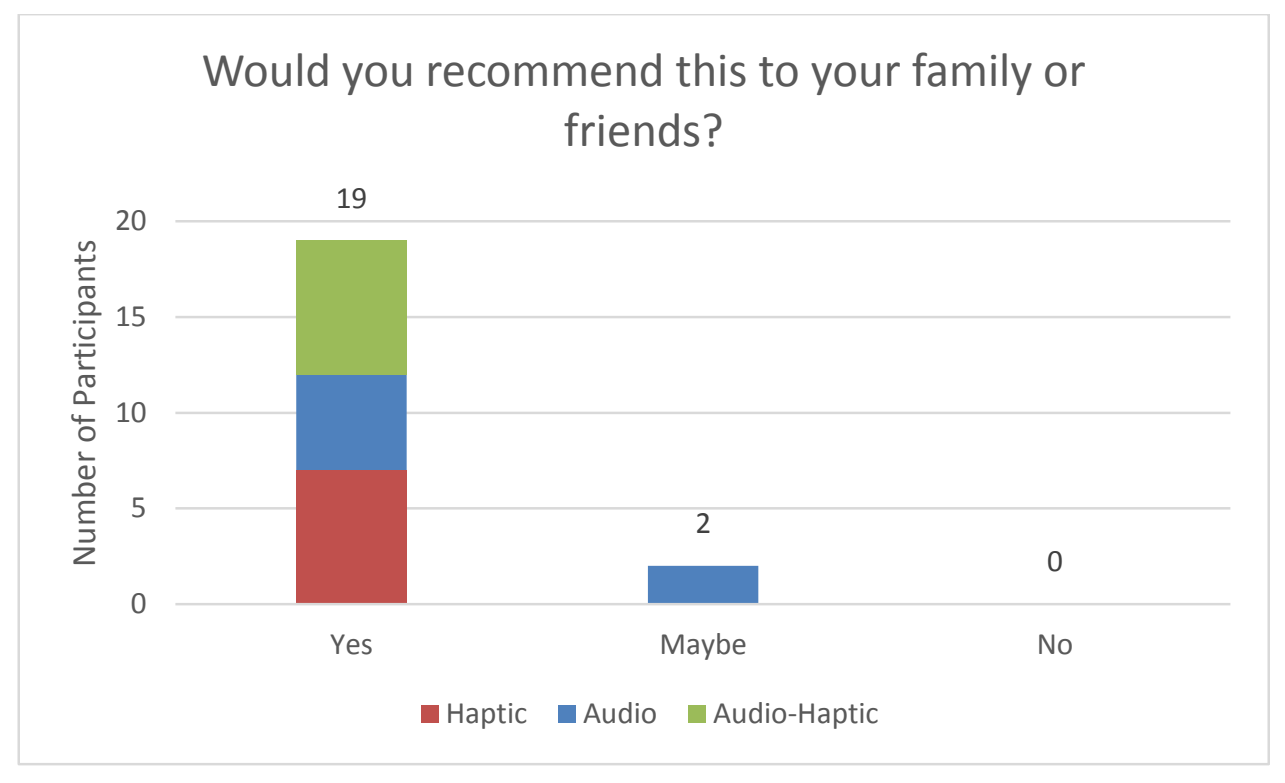

Figure 13. Participant responses on recommending the application to family or friends.

Nineteen participants said that they would recommend using this application to family or friends (Figure 13). The remaining two users responded maybe because they felt unsure about pushing products on their family and friends in general. Their uncertainty was not due to the effectiveness of the application. It is interesting to note that two-thirds of the participants that responded maybe to daily use would still recommend it to their family or friends. No participants said they would not recommend the application at all. 


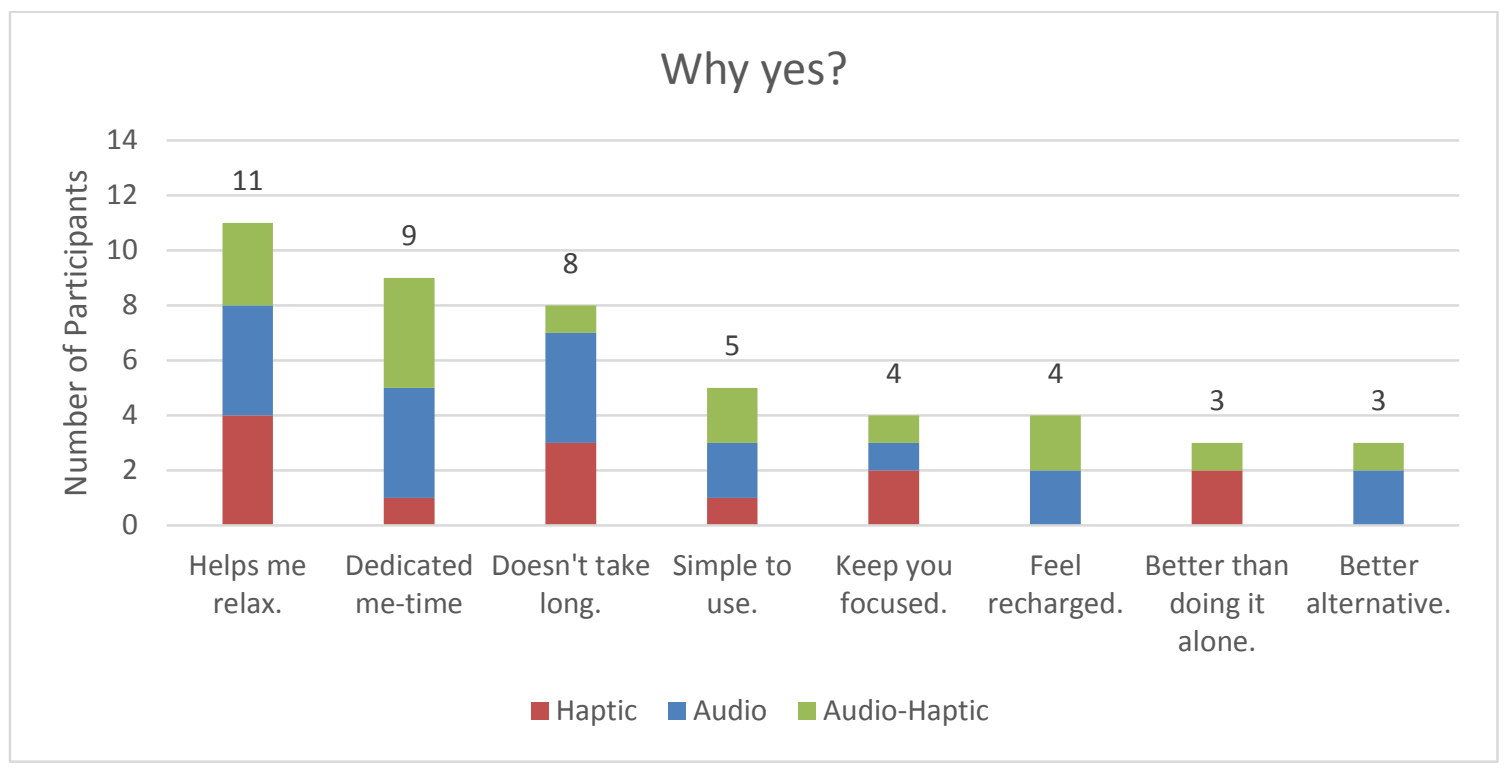

Figure 14. Reasons why participants would use the application daily.

Participants had a range of reasons why they would use the application on a daily basis (Figure 14). Eleven participants specifically said that the application helped them relax. Nine participants said that it was nice to use the application to dedicate a few minutes a day for yourself. Eight participants noted how it does not take much time at all. Five participants mentioned that it was simple to use. Four participants said that it kept them focused. Three users noted that they liked having a guide rather than doing it by themselves. Another three participants also commented that this is a better alternative to their current methods of relaxation, like eating, napping, or listening to music.

\section{Preferred Interaction Mode}

Each participant experienced both types of interactions: manual and biofeedback. On the third day, they chose which interaction to experience they wanted to experience a second time. 


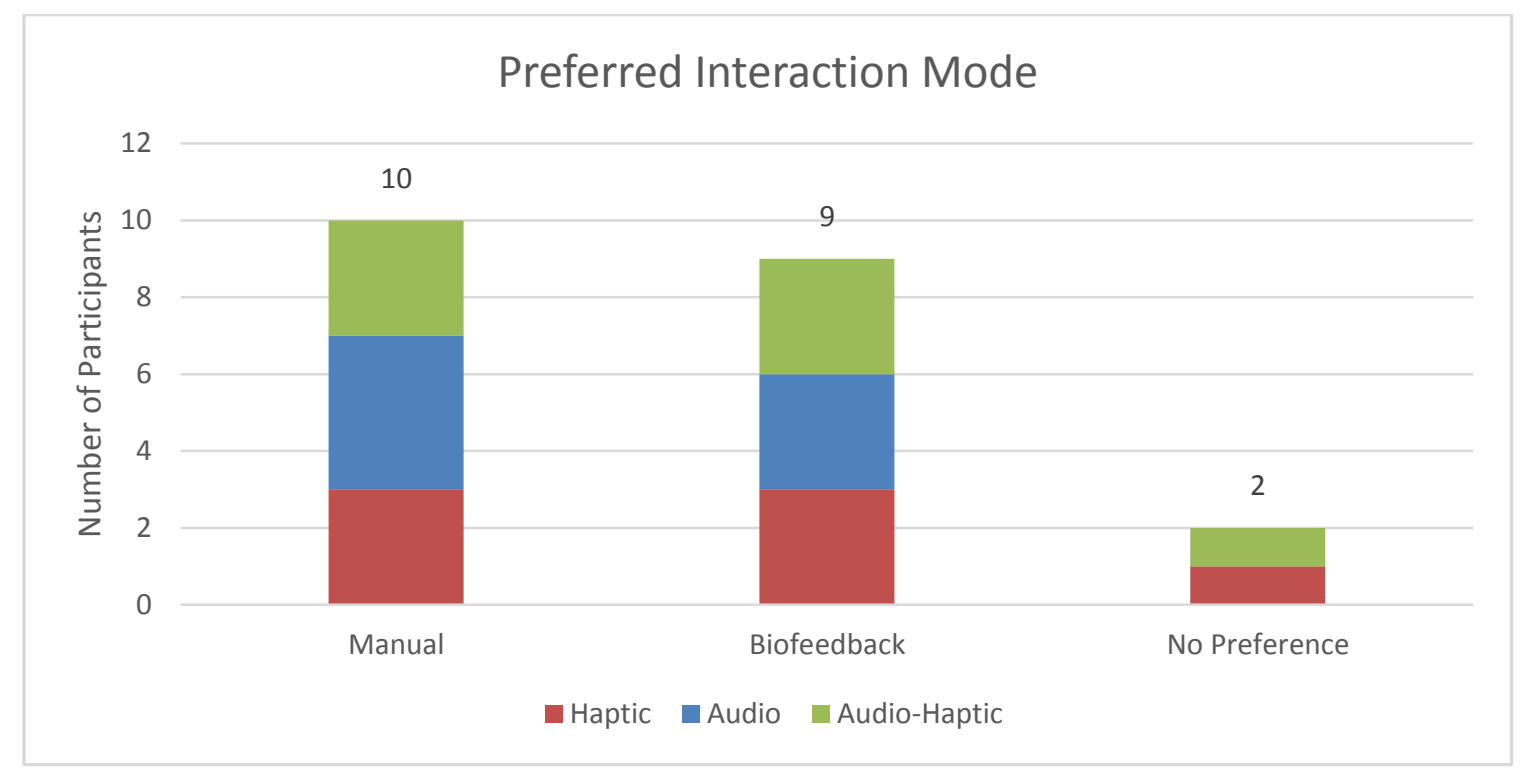

Figure 15. Preferred interaction mode.

Out of the 21 participants, 11 chose the manual mode, while 10 chose the biofeedback mode. Two participants clarified that they did not have a preference over either interaction mode. Removing these two users from the preferred interaction count still leaves the count at 10 (48 percent of participants) for the manual mode and 9 (43 percent of participants) for the biofeedback mode (Figure 15).

\section{Relaxation Response}

\section{Calculated Change in Relaxation}

The stress survey also contained 5-point Likert scale items of various adjectives adopted from the Stress Arousal Checklist (King, 1983). Stress adjectives were weighted according to the user's ranking and its negative or positive connotation, and summed together to quantify the user's current stress level. We calculated the user's change in stress by finding the difference before and after each meditation sit. An 
increase in objective relaxation was inferred from a decrease in quantitative stress. This value was normalized then mapped to a \pm 10 scale. Where -10 is maximum possible decrease in relaxation, 0 is no change, and +10 is maximum possible increase in relaxation. So someone with a calculated relaxation value of +10 , came into the session with the lowest possible relaxation level, and had the highest possible relaxation level after using the mobile phone application.

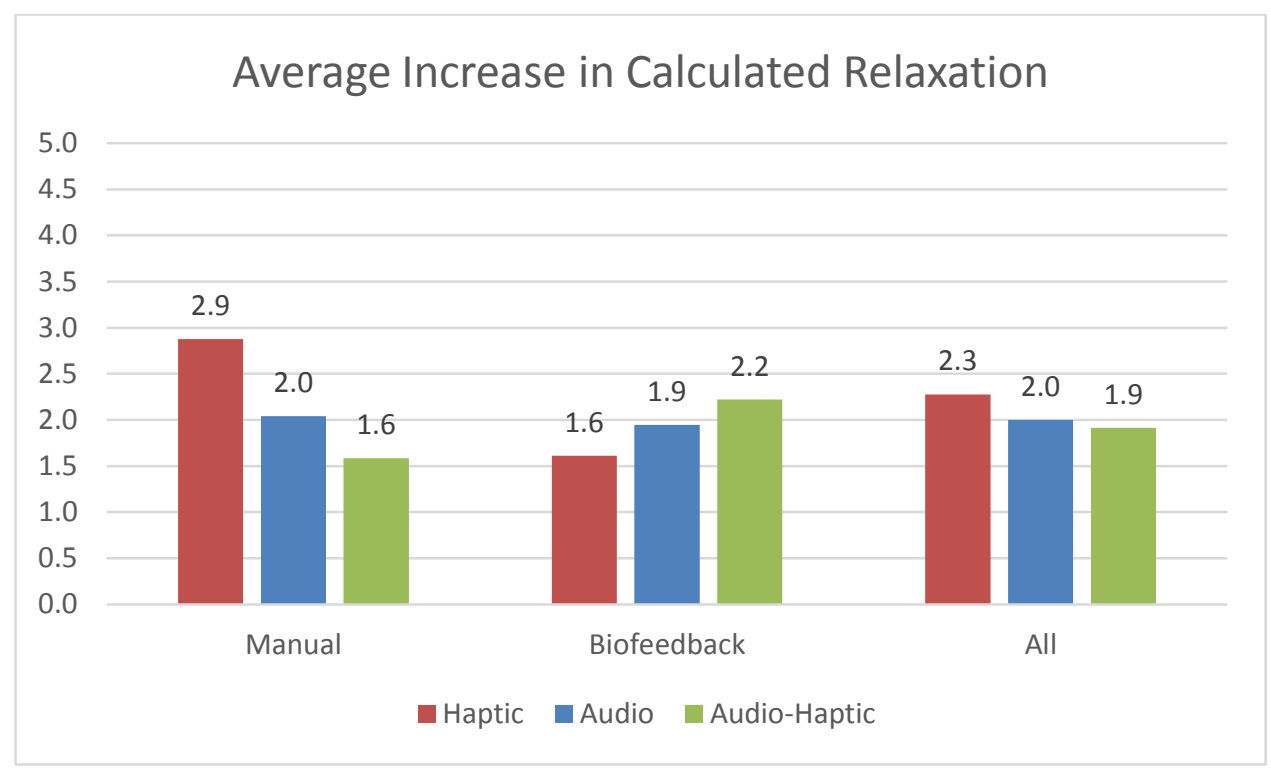

Figure 16. Average mean increase in calculated relaxation.

Overall, participants in all sessions experienced an increase in calculated relaxation, as inferred from a decrease in calculated stress (Figure 16). On average the haptic group experienced the greatest increase in calculated relaxation with an average value of 2.3. This is followed by the audio group at 2.0 and the audio-haptic group at 1.9. If we were to look at the data even further by type of interaction, the haptic 
feedback in manual interaction mode was the greatest at 2.9. It also has the greatest difference between manual interaction and biofeedback interaction mode. The biofeedback interaction of the haptic mode is extremely low at 1.6. For the audio group, the manual and biofeedback group are fairly close at 2.0 and 1.9 respectively. Interestingly, the audio-haptic group had the opposite pattern from the haptic group. The biofeedback sessions yielded a high increase in relaxation at 2.2, compared to the manual session at 1.6. The manual session of the audio-haptic group was also the lowest increase in relaxation in all sessions.

\section{Subjective Change in Relaxation}

The stress survey contained an analog scale that read very tense to very relaxed. Participants marked their current relaxation state on the scale before and after each meditation sit. The participant's mark was converted to a real number on a scale of 1.00 (very tense) to 5.00 (very relaxed). We calculated the user's subjective change in relaxation by the difference of the converted values. Again, this value was again normalized then mapped to a \pm 10 scale.

In general, each group experienced an increase in relaxation state (Figure 17). Overall, users did feel an increased state of relaxation. On average, the three groups were fairly close to each other. 


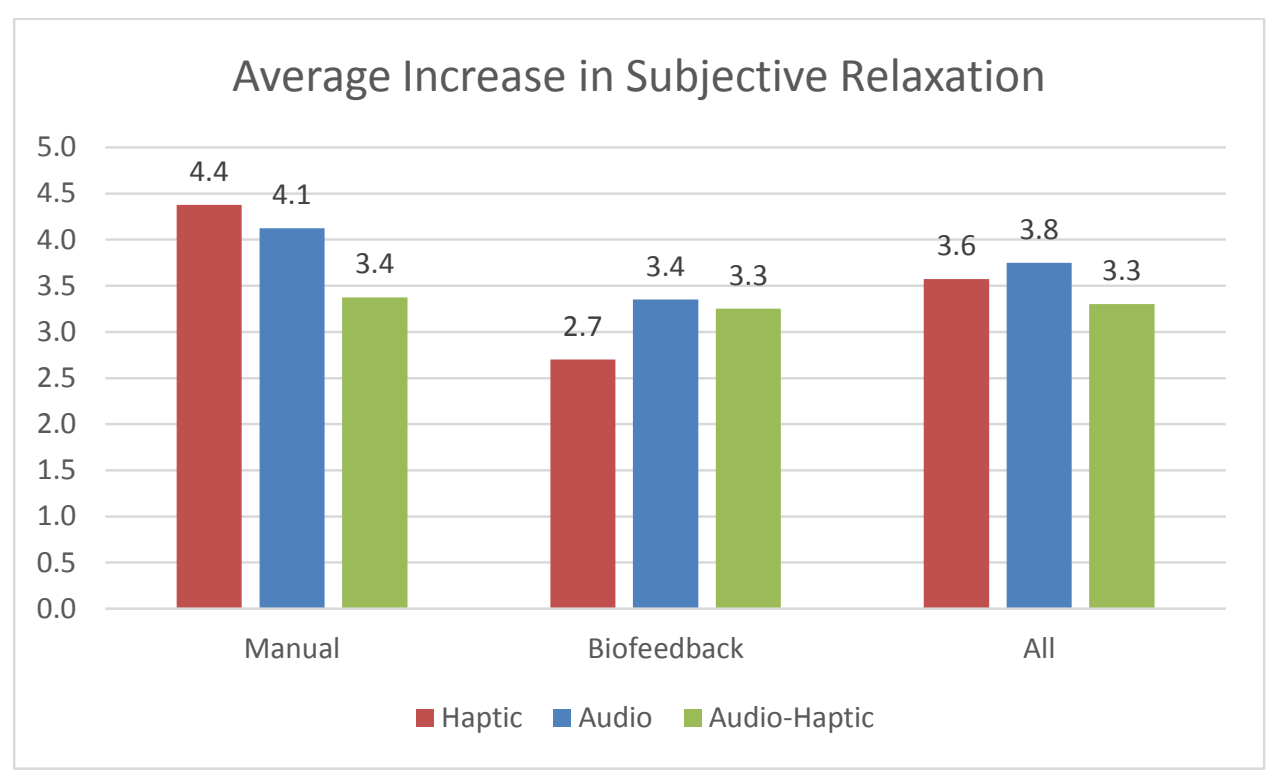

Figure 17. Average increase in subjective relaxation.

The audio group led the greatest average increase in subjective relaxation at 3.8, followed by the haptic group at 3.6 and the audio-haptic group at 3.3. However, if we were to break down these groups further by interaction mode, the haptic group obtained the greatest average change in relaxation at a value of 4.4. This is closely followed by the audio manual group at 4.1. The lowest value was the haptic biofeedback sessions at 2.7. The manual and biofeedback sessions of the audio-haptic group yielded very similar numbers, 3.4 and 3.3 respectively.

\section{Physical Response}

\section{Breathing Rate}

Users did experience a decrease in breathing rate during the session overall. Table 6 indicates a breakdown of the average breathing rate values observed in each modality and interaction mode. 


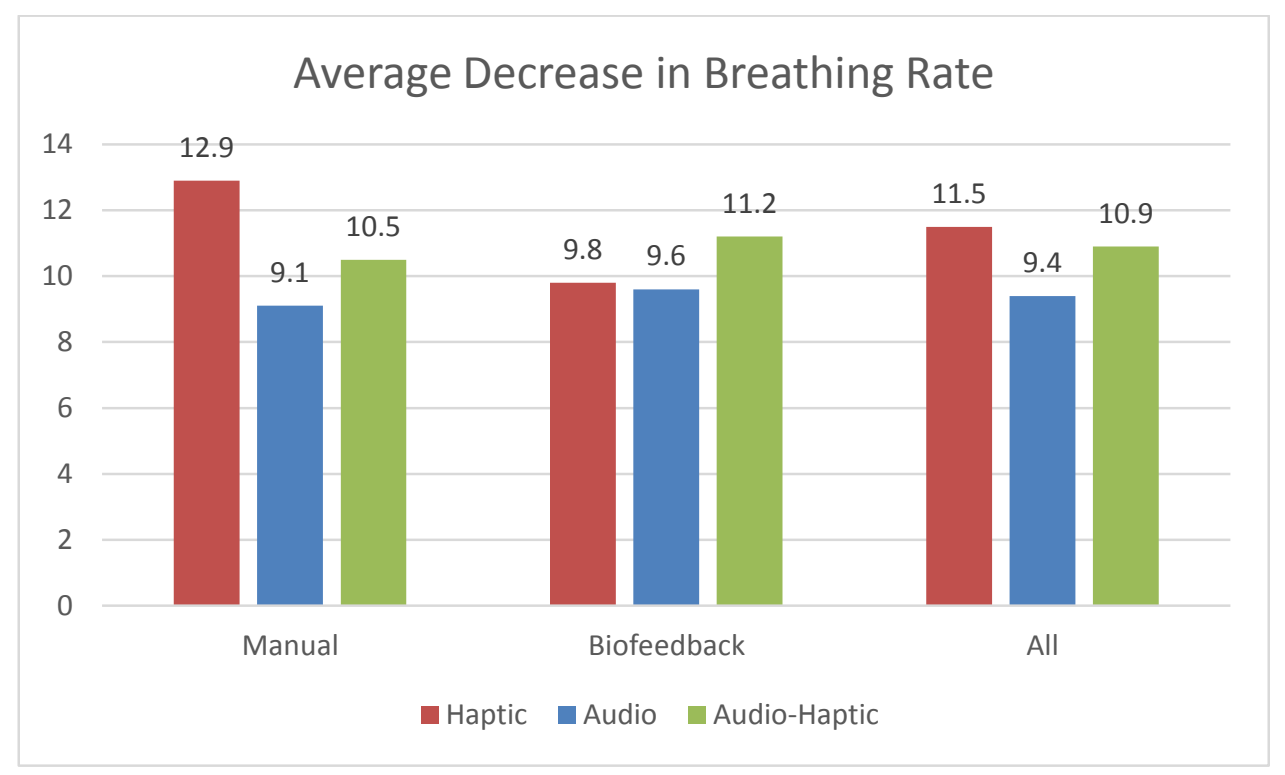

Table 6. Average highest, lowest, and change in breathing rate (BR) values by group and interaction mode.

Difficulty of the session indicates the observed level of difficulty the user had in following the breathing guide. Each session was described using the following adjectives: gradual, flat, and bumpy (Figure 18). A gradual section is characterized by a steady decrease in average BR. A flat section is characterized by a stable value of average BR. A bumpy section is characterized by an unstable BR.
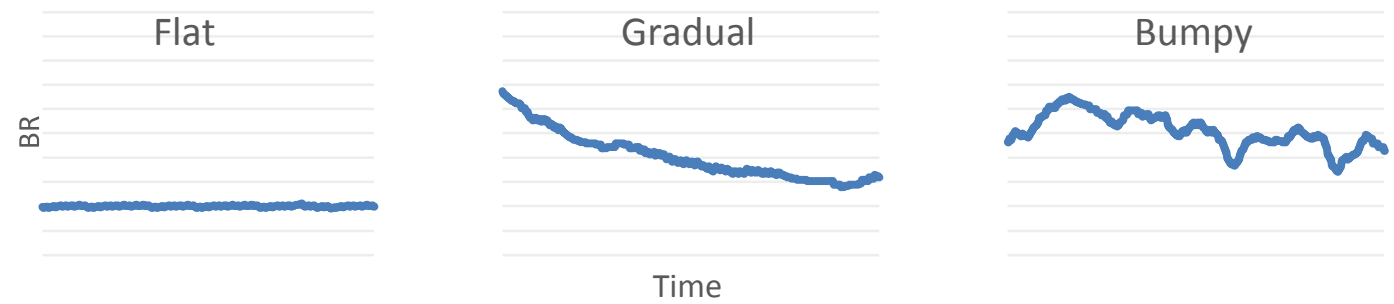

Figure 18. Graph descriptions of breathing rate (BR) over the session duration: (a) flat, (b) gradual, and (c) bumpy. 
Performance during the manual sessions was divided up into five different categories based on the order observed of the previous characteristics as shown in Table 7: (1) gradual and flat, (2) flat, (3) bumpy and flat, (4) flat and bumpy, and (5) bumpy. Similarly, biofeedback sessions were divided into the following five categories as shown in Table 7: (1) gradual and flat, (2) gradual, (3) bumpy and gradual, (4) gradual and bumpy, and (5) bumpy.

Table 7. Examples of graph descriptions for manual and biofeedback interaction sessions.

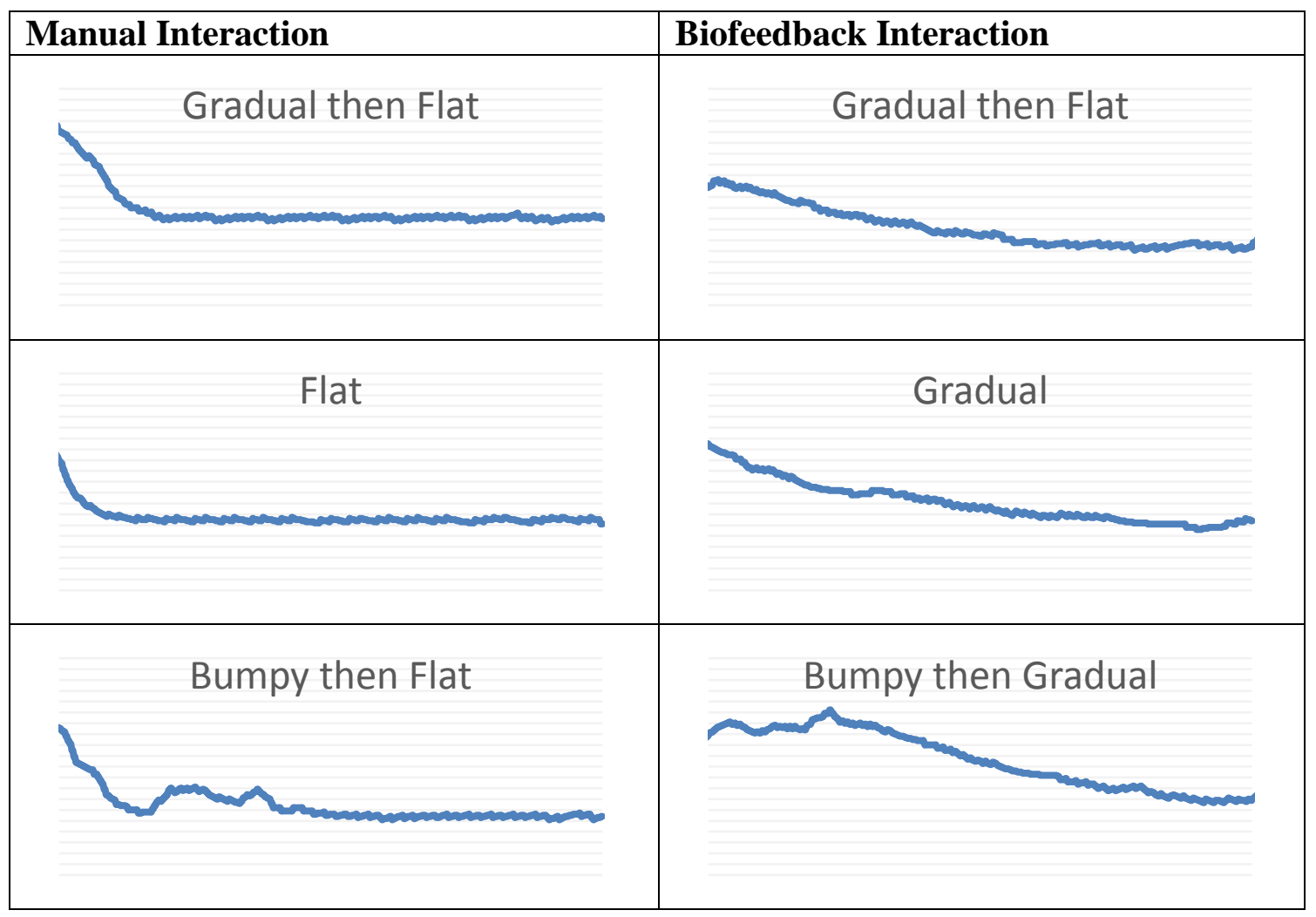


Table 7. Continued

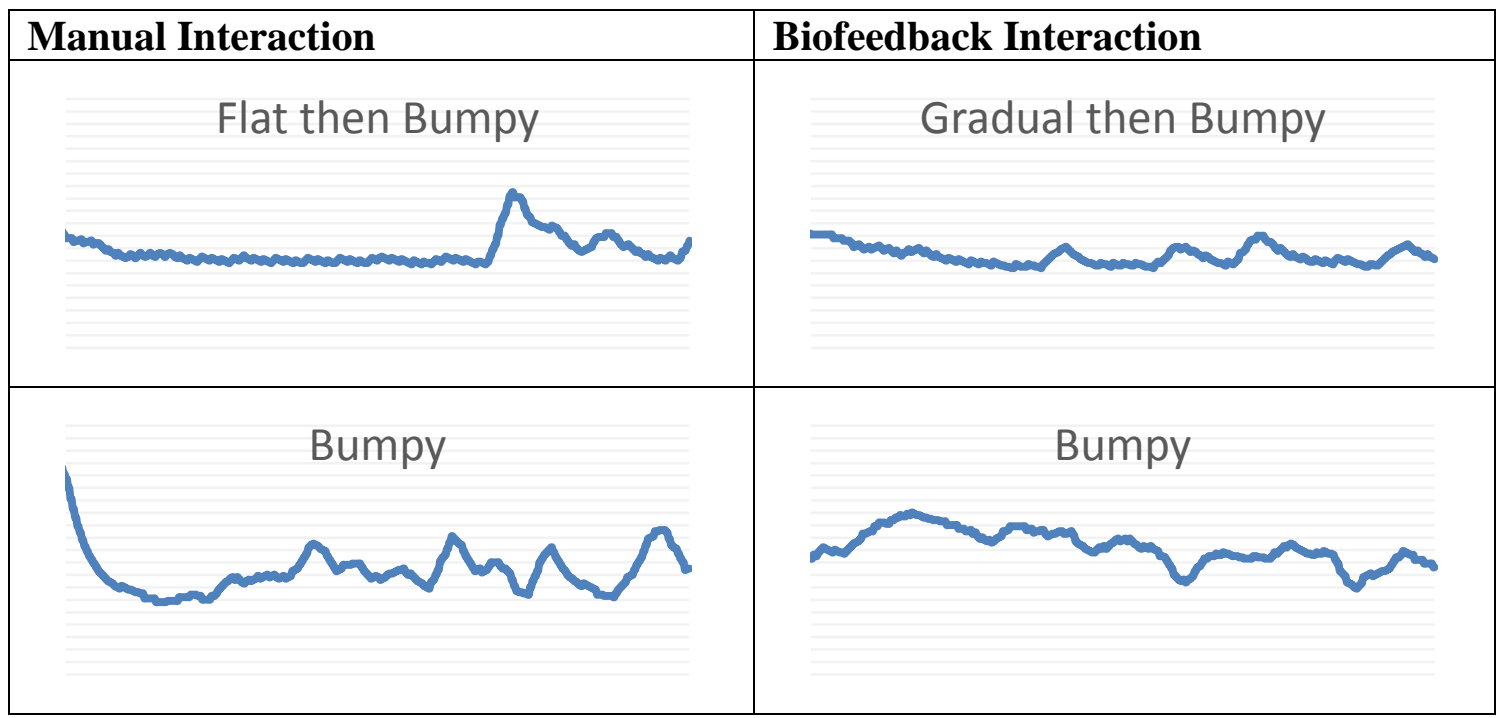

Gradual and flat patterns are desirable, as it indicates the user was able to follow the guide within reason. They were then reclassified as smooth. Figure 19 indicates the division of patterns among the modality groups. 


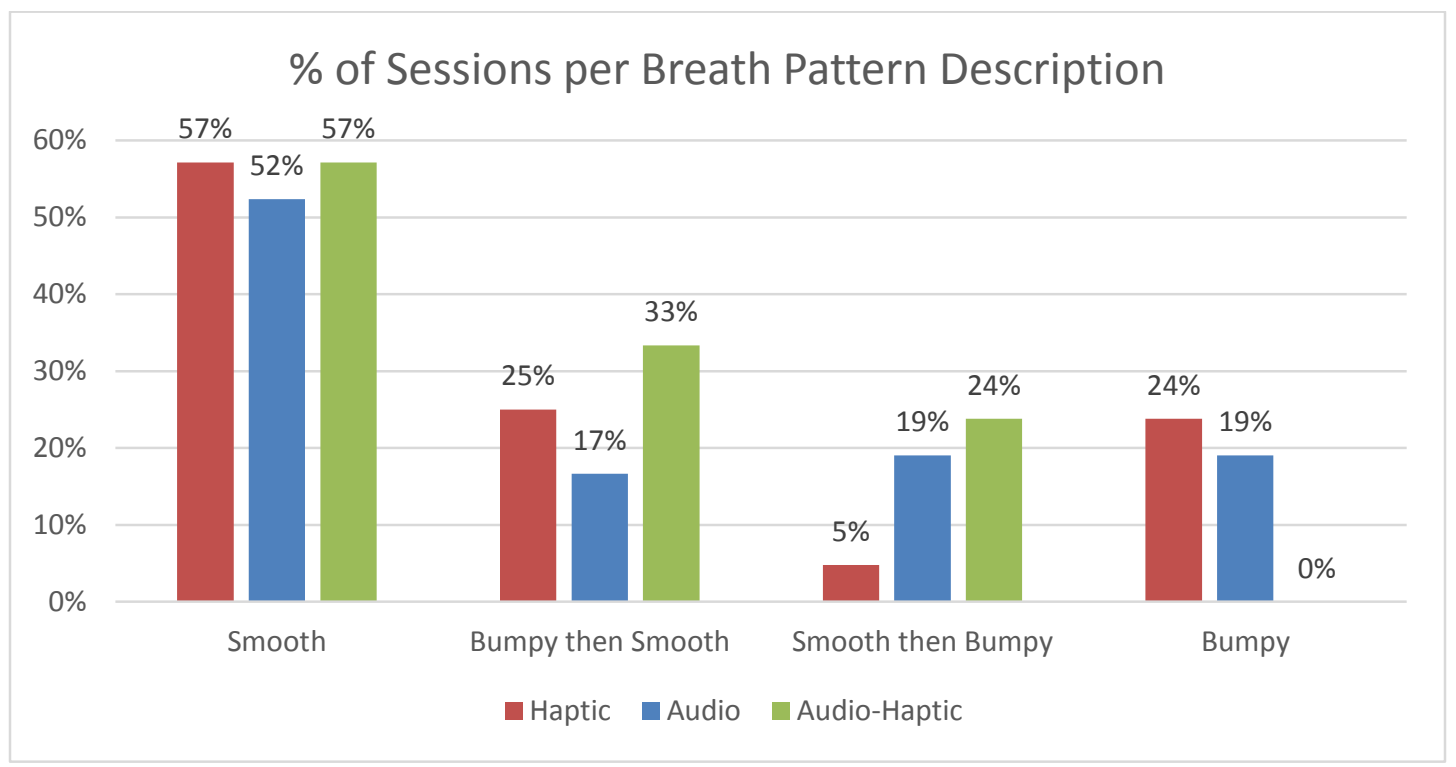

Figure 19. Breakdown of sessions for each breath pattern description.

In the majority of sessions, the participant was able to follow the guide. 57 percent of sessions in the haptic and the audio-haptic guide resulted in smooth breath patterns. This was closely followed by 52 percent of sessions in the audio group. 33 percent of users in the audio-haptic group had a breath pattern classified as bumpy then smooth. 24 percent of sessions in the audio-haptic group the inverse breath pattern, smooth then bumpy. No one in the audio-haptic group experienced a completely bumpy breath pattern. Looking at the audio group, the remaining sessions were evenly split: 17 percent bumpy then smooth, 19 percent smooth then bumpy, and 19 percent bumpy then smooth. In the haptic sessions, 25 percent of the sessions were classified as bumpy then smooth, and 24 percent of the sessions were classified as completely bumpy. Only 5 percent of the haptic sessions were considered smooth then bumpy. 
Difficulty following was calculated by determining the fraction of time the user's breath was bumpy throughout the duration of the session. It is on a scale from 0 (completely smooth) to 10 (completely bumpy during the majority of the session).

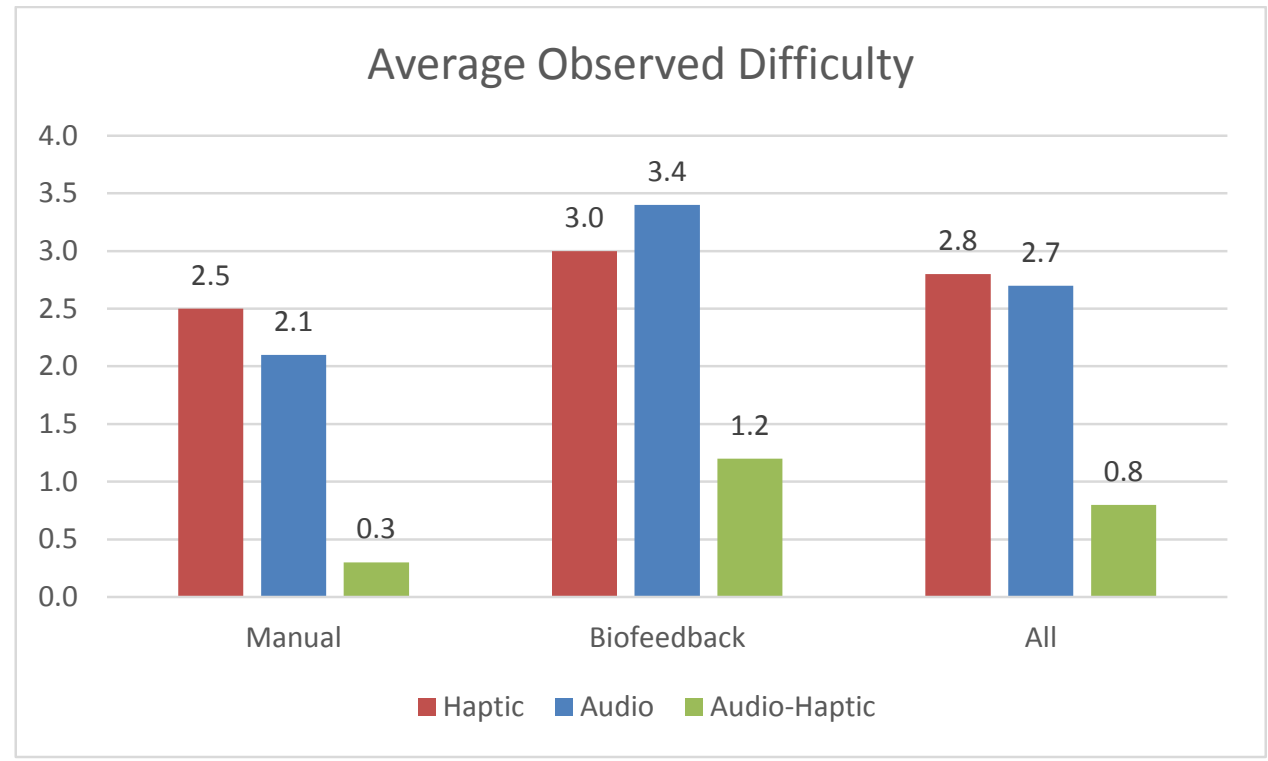

Figure 20. Average observed difficulty.

Out of the three guidance feedback systems, the audio-haptic guidance system was significantly the easiest to follow (Figure 20). The average difficulty participants had following the audio-haptic guidance was 0.8 versus 2.8 and 2.7 for haptic guidance and audio guidance respectively. For manual interaction, participants had difficulty following the system 0.3 of the session time versus 2.5 and 2.1 for haptic guidance and audio guidance respectively. For biofeedback interaction, participants had difficulty following the 1.2 of the session time versus 3.0 and 3.4 for haptic guidance and audio guidance respectively. 


\section{Posture}

The posture value from the sensor indicated the degree a person was reclined while sitting. We monitored this value, expecting the more relaxed a participant, the more reclined they would settle into as the session went on. However, most users remained stagnant or reclined minimally throughout the duration of the session. Since there were very few users that reclined significantly, this data was not used for further analysis.

\section{Heart Rate Variance}

Overall, users experienced no change or slight decrease in heart rate variance. This is unexpected as many sources state that a decrease in breathing rate should yield a higher heart rate variance. This discrepancy could be due to the user breathing improperly (i.e. through their chest instead of using their diaphragm). This also could be a result of inadequate sensor placement. This data was also not used for further analysis. 


\section{DISCUSSION}

This section is divided into four sub-sections. The first three sub-sections discuss the results relating to one of the previously stated research questions: preferred interaction mode, haptic guidance, and audio-haptic guidance. The last sub-section goes over the limitations and future work of this study.

\section{Preferred Interaction Mode}

It was expected that biofeedback control would be the preferred type of interaction. In particular yogic breathing practices, the objective is to bring awareness to the present by focusing on the body and breath. If the biofeedback interactive system is successful, it would allow the user to focus solely on their breath and not be concerned or preoccupied about manipulating the system itself. In actuality, the preferred interaction type was split among the participants: 48 percent for manual interaction, 43 percent for biofeedback interaction, and 9 percent with no preference. It appears that the favored type of interaction is simply dependent on personal preference. Some participants wanted to have direct control over choosing the breathing rate and did not want to release any control to the system. Other participants liked that they could give up some control, and just focus on their breath.

Both types of interaction are still desirable among users. Of the twenty-one participants, sixteen made at least one positive comment regarding the manual interaction, closely followed by fifteen users concerning the biofeedback interaction. One of the participants who had no preference over a group stated, "I like having the 
option of both. If I really wanted to relax, and I only had nine minutes, then I'd want to do the [manual] one because I would just start right there. But if I maybe had time to do both, then I would start with the [biofeedback] one and slow my breathing down and then do the [manual] one again after it's already there." It appears that the majority of participants liked the option of being able to choose their own breathing rate to follow, but also liked the idea of easing into the deep breathing.

The main complaint regarding the biofeedback system was that it started off too quickly. This perspective could be a result of comparison with prior exposure to the training application used in the informational section of the first day. The breathing guide in the training session was set to 6 BPM. Additionally, when user enters the manual session the breathing rate is initially set to $6 \mathrm{BPM}$. As a result of having either or both of these experiences before the biofeedback system, the breathing guide would be alarmingly fast. This is interesting, because essentially the system is mirroring back their current breathing rate. Adjustments could be made to the system to make a maximum breathing rate that is still comfortably slow, as to not startle the participant. One participant made an astute observation regarding their breath: "I felt like yesterday when I was doing [the manual session]. I was relaxed but it was like a little boring. But this gave me something to work towards. Like it showed me how fast my breathing was. And I was like whoa! Okay! I need to slow it down. So yeah, I did like that. I thought it was interesting." As the system carried on, six users commented that they felt that the system began to prompt them to breathe too slowly. Additionally, four participants explicitly said they felt uncomfortable as a result of the system starting too fast or too slow. This is 
again the result of system's current limitations. The system would increase the breathing rate if people had a hard time matching it; however, once they were able to reach the target breathing rate, it would challenge the participant to breathe slower once more. A solution could be to stabilize the system once it finds a good match.

\section{Haptic Guidance}

As touch is incredibly intimate and important for well-being. By stimulating the tactile sense, the user is provided a personal space where the experience is solely their own. The results of the study support our hypothesis that haptic guidance would be effective on its own. In fact, overall, it appears that the manual haptic guidance was the most effective out of all interaction modality cases.

A few users in the haptic group noted they liked the pulses because they were subtle or reminiscent of the cat purring or a heartbeat. There does appear to be a negative initial association with a phone vibrating. Some participants commented that they felt that they were receiving a call. However, by the end of the three sessions, this negative association was faded once the participants became familiar with the vibration pulses as a breathing guide. Another participant mentioned that the fact that the phone was encased in a pillow did help remove this negative association as well.

Out of the three modality groups, the majority of participants in the haptic group were partial to the manual interaction. All seven members of the haptic group had a positive comment regarding the manual interaction mode, compared to only five and four participants in the audio and audio-haptic group respectively. Users in the haptic group also had the least amount of negative comments to give about the manual 
interaction mode: three users had something negative to say, compared to five and four users in the audio and audio-haptic group respectively. However, the majority of participants in the haptic group did not like the biofeedback interaction at all. Only 23 percent of the positive comments regarding the biofeedback system were from the haptic group. Additionally, only one haptic user liked that the system eased into the deep breathing, compared to six and four of the audio and audio-haptic group respectively. The haptic group's preference for the manual interaction is also indicative in the emotional responses for both calculated and subjective relaxation.

Out of the three modality groups, the haptic group's manual and biofeedback sessions had the widest discrepancy in relaxation increase. For the average change in calculated relaxation, there was a difference of 1.3 between manual and biofeedback sessions, while the audio and audio-haptic group had gaps of 0.1 and 0.6 respectively. Similarly for the average change in subjective relaxation, the haptic group's manual and biofeedback sessions had the greatest difference of 1.7, while audio and audio-haptic groups had a gap of 0.7 and 0.1 respectively. It is noteworthy that the manual haptic sessions yielded the highest average change in both calculated and subjective relaxation overall.

It is interesting to also note that these differences in the haptic manual and biofeedback sessions are also reflected in the physical responses examined. Overall, participants in the manual haptic session on average achieved the greatest change in decreasing their breathing rate by 12.9 BPM. The haptic group also had the widest 
discrepancy, 3.1 BPM, between interaction modes for change in breathing rate. The audio and audio-haptic group had a gap of 0.5 BPM and 1.3 BPM respectively.

On average, the haptic group did have the hardest time following the breathing guide. 24 percent of the session breathing patterns was described as completely bumpy, versus 19 percent and 0 percent for audio and audio-haptic groups respectively. However, it is interesting to notice that only 5 percent of haptic sessions had a breathing pattern of smooth then bumpy, as compared to 19 and 24 percent of users. This might indicate that if the participant has a good handle on following the guide, they are more focused throughout the duration of the session.

\section{Audio-Haptic Guidance}

It was expected that the addition of haptic feedback would enhance the audio based guidance. There have been a few studies that support the effectiveness of vibroacoustic therapy for relaxation (Wigram, 1996; Patrick, 1999; Brewer et al., 2004) and that the simultaneous stimulation of the auditory and tactile senses can be more effective than stimulating one at a time (Dijk et al. 2009; Dijk et al. 2010). Additionally in the particular case of paced breathing, in the previously mentioned study, Breathe with the Ocean (Dijk et al. 2010) that featured a breathing guidance installation, it was noted that most users found the synchronization between the wave-like patterns from the haptic blanket and the audio waves pleasing.

The general feedback interviews from our study supported the comfortable effect from the combined stimulation. A few participants remarked that they liked how the sounds and vibrations worked together, leading to a more immersed feeling. Participant 
$\mathrm{H}$ reflected, "I actually found the gong noise a lot more relaxing... for some reason I realized this is actually a good noise. I like this... And I felt that... had the vibrations not been there I don't know if it would have the same effect."

41 percent of the positive comments for the biofeedback interaction came from the audio-haptic group, compared to 35 percent and 23 percent of the audio and the haptic group respectively. They also had the less amount of negative things to say about the biofeedback interaction: 22 percent versus 44 and 33 percent for the audio and the haptic group respectively. Only one participant in the audio-haptic group commented that the system started off too fast, compared to four users in the audio and three users in the haptic group.

Interestingly, the audio-haptic group experienced the greatest increase in calculated relaxation for biofeedback sessions, 2.2 versus 1.6 and 1.9 for the haptic and audio group respectively. However, the audio-haptic group also experienced the least amount of calculated relaxation in manual sessions, 1.6 versus 2.9 and 2.0. For subjective relaxation, audio-haptic manual and biofeedback sessions resulted in a similar value, 3.4 and 3.3 respectively. This is interesting to note because the other two groups experienced a 0.7 to 1.7 difference between manual and biofeedback sessions.

Overall, the audio-haptic group did have a significantly easier time following the guide out of the three modalities in both interaction modes with a difficulty value of 0.8 overall versus 2.8 and 2.7. However, it did not necessarily enhance relaxation more over one stimulation alone, and in some cases hindered it. This supports the previous results (Wongsuphasawat et al., 2012), in which smooth controlled breath does not necessarily 
lead to a greater sense of relaxation. That being said, participants still expressed pleasure of experiencing both stimulations simultaneously.

\section{Limitations and Future Work}

There are limitations with the interview and survey data due to self-report error. Participants may also have suffered from the "John Henry" effect, as they entered the study expecting to relax which may have provided a bias. There were also ceiling values in the survey questions, which affected responses of users who came into the session already in a relaxed state. The analog scale design (Appendix B) also led some users to fill in the circles rather than mark along the line, resulting in an integer value rather than a real number. In some cases, verbal instruction was necessary to prevent this. It would have also been effective to video record the meditation sit in order to observe how the user interacted with the app. It would also be good as a cross reference to help explain random peaks in the sensor data.

There are also additional limitations with the sensor used. There may be some error with the readings and delay in response of the user's current breathing rate. There is also potentially a timestamp discrepancy between the data from the sensor and from the mobile device. In future work, it would be beneficial to create a file within the application to contain start and end times along with the sensor and guide values. This would also allow us to get a more insight into how close the user was to the guide they were given.

Future work is necessary in order to validate the significance of our findings on a larger sample scale. It would also be beneficial to make improvements to the 
biofeedback system behavior to eliminate discomfort with the guide moving too slowly or quickly. Future work should also expose participants to experience all three modalities. 


\section{CONCLUSION}

This study investigated the integration of biofeedback and haptic stimulation in mobile paced breathing tools. In order to explore these areas, a mobile phone application was developed. The application was highly received overall among participants. On average, all combinations of interaction and breathing guide modalities resulted in an increase in calculated and subjective relaxation.

Our qualitative analysis suggests that both manual and biofeedback modes are desirable. However, the manual mode resulted in greater average calculated and subjective relaxation. Manual mode was observed to be easier to follow overall. This suggests that biofeedback implementation is not vital in attributing to a greater sense of well-being. This information could potentially aide in therapeutic settings, as it may not be necessary for counselors and the high stress population to invest in expensive biofeedback equipment for stress relief.

The findings of this study also support the effectiveness of haptic guidance on its own. Although, the haptic breathing guide was observed to be the most difficult to follow, manual haptic guidance resulted in the greatest calculated and subjective relaxation. It also led to the greatest decrease in breathing rate. This may be greatly applicable to various situational use. There may be certain conditions where audio

guidance is not viable (e.g. too much environmental noise or desire for silence). Many people also have a personal mobile device which contains a motor, and thus, can take advantage of haptic guidance benefits. 
Lastly, simultaneous audio-haptic guidance led to a greater decrease in breathing rate over audio guidance, and was the overall easiest to follow. However, it did not necessarily enhance relaxation more over one stimulation alone, and in some cases hindered it. Multimodal audio-haptic stimulation may be beneficial in aiding focus to meet a particular task, but this may impede the user's full potential to relax. 


\section{REFERENCES}

Brown, R. P., \& Gerbarg, P. L. (2005). Sudarshan kriya yogic breathing in the treatment of stress, anxiety, and depression: Part II-clinical applications and guidelines. Journal of Alternative \& Complementary Medicine, 11(4), 711-717.

Cheung, Y. L., Molassiotis, A., \& Chang, A. M. (2003). The effect of progressive muscle relaxation training on anxiety and quality of life after stoma surgery in colorectal cancer patients. Psycho-Oncology, 12(3), 254-266.

Dijk, E. O., Weffers-Albu, A., \& De Zeeuw, T. (2009). A tactile actuation blanket to intensify movie experiences with personalised tactile effects. Paper presented at the International Conference on Intelligent Technologies for Interactive Entertainment, pp. 2-3.

Dijk, E., \& Weffers-Albu, A. (2010). Breathe with the ocean: A system for relaxation using audio, haptic and visual stimuli. Paper presented at the Proceedings of the EuroHaptics Special Symposium: Haptic and Audio-Visual Stimuli: Enhancing Experiences and Interaction, pp. 57-60.

Dijk, E. O., Nijholt, A., van Erp, J. B., Kuyper, E., \& van Wolferen, G. (2010). Audiotactile stimuli to improve health and well-being. Preliminary positon paper presented at the Proceedings of the EuroHaptics Special Symposium: Haptic and Audio-Visual Stimuli: Enhancing Experiences and Interaction, pp. 1-10.

emWave technology. (2008). Retrieved January 13, 2015, from http://www.heartmath.com/emwave-technology/

Gagne, D., \& Toye, R. C. (1994). The effects of therapeutic touch and relaxation therapy in reducing anxiety. Archives of Psychiatric Nursing, 8(3), 184-189.

Goldin, P. R., \& Gross, J. J. (2010). Effects of mindfulness-based stress reduction (MBSR) on emotion regulation in social anxiety disorder. Emotion, 10(1), 83.

Granath, J., Ingvarsson, S., von Thiele, U., \& Lundberg, U. (2006). Stress management: A randomized study of cognitive behavioural therapy and yoga. Cognitive Behaviour Therapy, 35(1), 3-10.

Grossman, P., Niemann, L., Schmidt, S., \& Walach, H. (2004). Mindfulness-based stress reduction and health benefits: A meta-analysis. Journal of Psychosomatic Research, 57(1), 35-43. 
The impact of stress. (2015). Retrieved January 30, 2015, from

http://www.apa.org/news/press/releases/stress/2012/impact.aspx

Inner balance: An innovative approach to improving wellness through training, education and self monitoring. (2013). Retrieved January 13, 2015, from http://www.heartmath.com/innerbalance/

Jin, P. (1992). Efficacy of tai chi, brisk walking, meditation, and reading in reducing mental and emotional stress. Journal of Psychosomatic Research, 36(4), 361-370.

King, M., Burrows, G., \& Stanley, G. (1983). Measurement of stress and arousal: Validation of the stress/arousal adjective checklist. British Journal of Psychology, 74(4), 473-479.

Lupien, S. J., McEwen, B. S., Gunnar, M. R., \& Heim, C. (2009). Effects of stress throughout the lifespan on the brain, behaviour and cognition. Nature Reviews Neuroscience, 10(6), 434-445.

Meek, S. S. (1993). Effects of slow stroke back massage on relaxation in hospice clients. IMAGE: The Journal of Nursing Scholarship, 25(1), 17-22.

Patrick, G. (1999). The effects of vibroacoustic music on symptom reduction. Engineering in Medicine and Biology Magazine, IEEE, 18(2), 97-100.

Pitstick, B. (2015). Wearable \& fitness tech trends- going mainstream. Retrieved January 30, 2015, from http://www.moorinsightsstrategy.com/research-paper-ces2014-wearable-fitness-tech-trends-going-mainstream/

Romberger, J. (n.d.). Levels of interactivity. Retrieved January 11, 2015, from http://ww2.odu.edu/ jromberg/439sp07/439activitylevels.html

Sandlund, E. S., \& Norlander, T. (2000). The effects of tai chi chuan relaxation and exercise on stress responses and well-being: An overview of research. International Journal of Stress Management, 7(2), 139-149.

Seaward, B. L. (2013). Managing stress: Principles and strategies for health and wellbeing. Jones \& Bartlett Publishers.

Smith, C., Hancock, H., Blake-Mortimer, J., \& Eckert, K. (2007). A randomised comparative trial of yoga and relaxation to reduce stress and anxiety. Complementary Therapies in Medicine, 15(2), 77-83.

Thieme, A., Wallace, J., Johnson, P., Lindley, S., McCarthy, J., Olivier, P., et al. (2012). Can we introduce mindfulness practice through digital design. Paper presented at 
the Proceedings of the 26th BCS Conference on Human Computer Interaction, pp. 12-14.

Vidyarthi, J., Riecke, B. E., \& Gromala, D. (2012). Sonic cradle: Designing for an immersive experience of meditation by connecting respiration to music. Paper presented at the Proceedings of the Designing Interactive Systems Conference, pp. 408-417.

Wernik, U. (2009). The use of prayer beads in psychotherapy. Mental Health, Religion and Culture, 12(4), 359-368.

What is RESPeRATE. (2014). Retrieved January 13, 2015, from http://www.resperate.com/what-is-resperate

Wigram, A. L. (1996). The effects of vibroacoustic therapy on clinical and non-clinical populations. Unpublished doctoral dissertation, University of London, England.

Wongsuphasawat, K., Gamburg, A., \& Moraveji, N. (2012). You can't force calm: Designing and evaluating respiratory regulating interfaces for calming technology. Paper presented at the Adjunct Proceedings of the 25th Annual ACM Symposium on User Interface Software and Technology, pp. 69-70. 
APPENDIX A

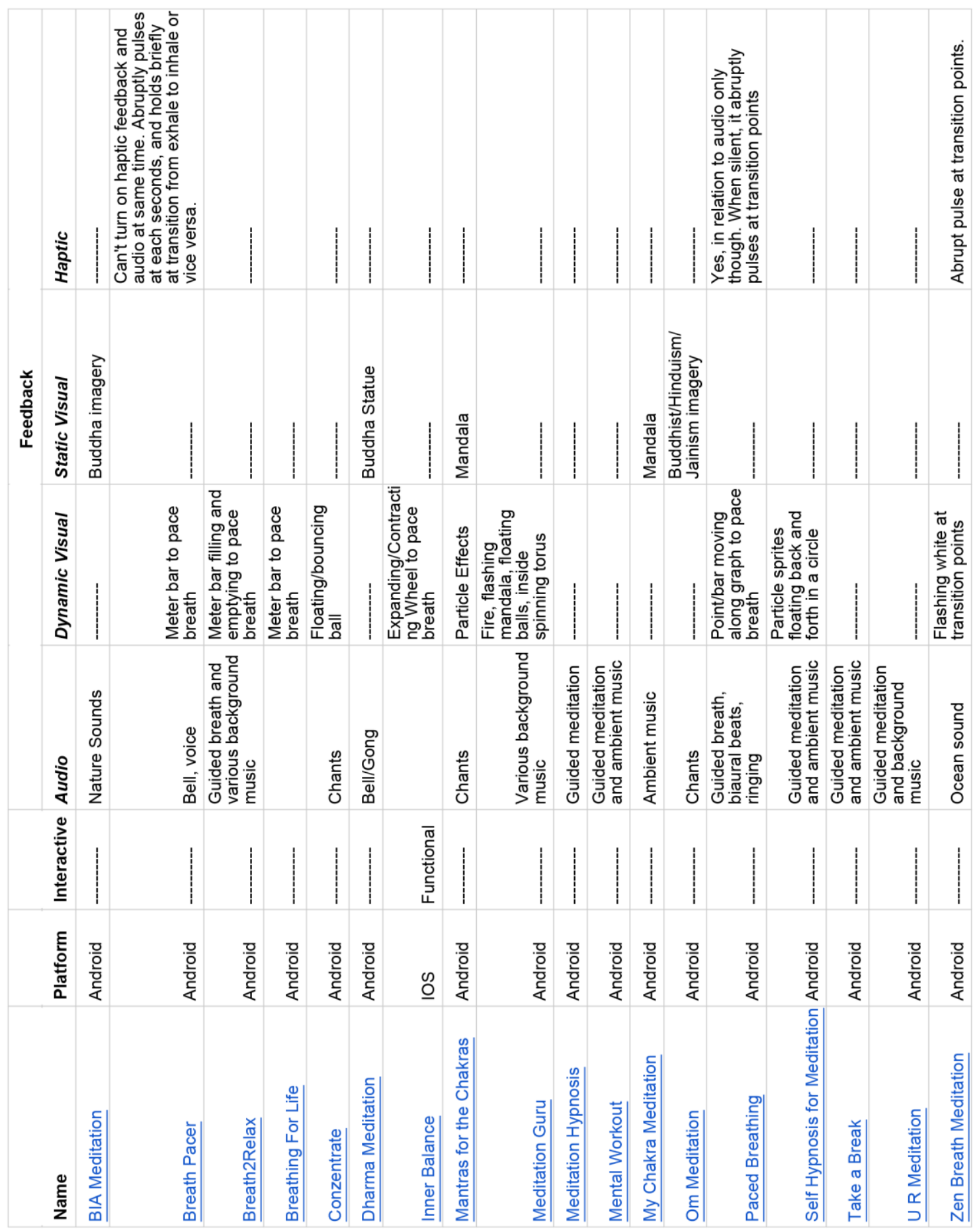




\section{APPENDIX B}

Please rate how much you personally identify with the following adjectives. There are no right or wrong answers. Try not to spend too much time on any statement. All that is important is you indicate how you feel at this very moment.

\begin{tabular}{|l|l|l|l|l|l|l|}
\hline & I feel... & $\begin{array}{c}\text { Strongly } \\
\text { Disagree }\end{array}$ & Disagree & Neutral & Agree & $\begin{array}{c}\text { Strongly } \\
\text { Agree }\end{array}$ \\
\hline $\mathbf{1}$ & active & 1 & 2 & 3 & 4 & 5 \\
\hline $\mathbf{2}$ & up-tight & 1 & 2 & 3 & 4 & 5 \\
\hline $\mathbf{3}$ & lively & 1 & 2 & 3 & 4 & 5 \\
\hline $\mathbf{4}$ & bothered & 1 & 2 & 3 & 4 & 5 \\
\hline $\mathbf{5}$ & distressed & 1 & 2 & 3 & 4 & 5 \\
\hline $\mathbf{6}$ & tense & 1 & 2 & 3 & 4 & 5 \\
\hline $\mathbf{7}$ & calm & 1 & 2 & 3 & 4 & 5 \\
\hline $\mathbf{8}$ & sleepy & 1 & 2 & 3 & 4 & 5 \\
\hline $\mathbf{9}$ & contented & 1 & 2 & 3 & 4 & 5 \\
\hline $\mathbf{1 0}$ & relaxed & 1 & 2 & 3 & 4 & 5 \\
\hline $\mathbf{1 1}$ & sluggish & 1 & 2 & 3 & 4 & 5 \\
\hline $\mathbf{1 2}$ & worried & 1 & 2 & 3 & 4 & 5 \\
\hline $\mathbf{1 3}$ & uneasy & 2 & 3 & 4 & 5 \\
\hline $\mathbf{1 4}$ & wergetic & 1 & 3 & 4 & 5 \\
\hline
\end{tabular}

Please mark your current relaxation/stress level anywhere along the line on the scale below.

Very Tense $\quad$ Tense $\quad$ Neutral




\section{APPENDIX C}

Introduction Interview

1. How do you feel about your general level of stress?

2. What do you try to do to relax? Any specific practices?
a. How long?
b. How often?
c. How effective?

i. How do you know it was effective?

3. What else do you like to do to manage stress?

4. Do you have any experience in deep breathing techniques?
a. How long?
b. How often?
c. How effective?

i. How do you know it was effective?

5. Do you use any type of technology (e.g. mobile phone apps, videos, etc.) to assist in stress management?
a. How long?
b. How often?
c. How effective? 
General Feedback Interview

1. How was your overall experience today?

2. What did you like?

3. What did you dislike?

4. Do you have any other comments you would like to add?

\section{Exit Interview}

1. How was your overall experience in the study?

2. What did you like about Application 1?

3. What did you dislike?

4. What did you like about Application 2?

5. What did you dislike?

6. Why did you choose $<1 / 2>$ for your last Day?

7. Would you use this app in your daily life?
a. If yes, why? Would you recommend this to your family or friends?
b. If not, why?

8. Do you have any other comments you would like to add? 